\begin{tabular}{|c|c|}
\hline Title & $\begin{array}{l}\text { A bundant distribution of TARP y - } 8 \text { in synaptic and extrasynaptic surface of hippocampal neurons and its major role in } \\
\text { A MPA receptor expression on spines and dendrites }\end{array}$ \\
\hline Author(s) & $\begin{array}{l}\text { Fukay a, Masahiro; Tsujita, Mika; Y amazaki, Maya; Kushiya, Etsuko; A be, Manabu; A kashi, Kaori; Natsume, Rie; } \\
\text { Kano, Masanobu; Kamiya, Haruyuki; W atanabe, Masahiko; Sakimura, Kenji }\end{array}$ \\
\hline Citation & $\begin{array}{l}\text { European Journal of Neuroscience, 24(8), 2177-2190 } \\
\text { https://doi.org/10.1111/.1460-9568.2006.05081.x }\end{array}$ \\
\hline Issue Date & $2006-10$ \\
\hline Doc URL & http:/hdl .handle.net $/ 2115 / 30133$ \\
\hline Rights & The definitive version is available at www.blackwell-synergy.com \\
\hline Type & article (author version) \\
\hline File Information & EJN24-8.pdf \\
\hline
\end{tabular}

Instructions for use 
Receiving Editor: Dr. J-M, Fritschy

EJN-2006-05-10768

\title{
Abundant distribution of TARP $\gamma-8$ in synaptic and extrasynaptic surface of hippocampal neurons and its major role in AMPA receptor expression on spines and dendrites
}

\author{
Masahiro Fukaya, ${ }^{1}$ Mika Tsujita, ${ }^{2}$ Maya Yamazaki, ${ }^{3}$ Etsuko Kushiya, ${ }^{3}$ \\ Manabu Abe, ${ }^{3}$ Kaori Akashi, ${ }^{3}$ Rie Natsume, ${ }^{3,4}$ Masanobu Kano, ${ }^{5}$ Haruyuki Kamiya, ${ }^{6}$ \\ Masahiko Watanabe, ${ }^{1}$ Kenji Sakimura ${ }^{3}$
}

Departments of ${ }^{1}$ Anatomy and of ${ }^{6}$ Molecular Anatomy, Hokkaido University School of Medicine, Sapporo 060-8638, Japan, ${ }^{2}$ Center for Transdisciplinary Research, Niigata University. Niigata 950-2181, Japan, ${ }^{3}$ Department of Cellular Neurobiology, Brain Research Institute, Niigata University, Niigata 951-8585, Japan, ${ }^{4}$ SORST, Japan Science and Technology Agency, Saitama 322-1002, Japan, and ${ }^{5}$ Department of Cellular Neuroscience, Graduate School of Medicine, Osaka University, Suita 565-0871, Japan

Running head title: TARP $\gamma-8$ in the hippocampus

The first two authors contributed equally to this work.

43 Pages with 7 Figures, 2 Supplemental Figures, and 0 Table Number of Words: Whole MS, 9397; Abstract, 248; Introduction, 496 
Please send correspondence and proofs to; Masahiko Watanabe

Department of Anatomy, Hokkaido University School of Medicine, Sapporo 060-8638, Japan:

FAX, 81-11-706-5031; TEL, +81-11-706-5032; E-mail, watamasa@med.hokudai.ac.jp

Key Words: Hippocampus, $\quad$ pyramidal

cell, transmembrane AMPA receptor regulatory protein, immunohistochemistry, immunoblot. 


\section{Abstract}

Transmembrane AMPA receptor regulatory proteins (TARPs) play pivotal roles in AMP A receptor trafficking and gating. Here we examined cellular and subcellular distribution of TARP $\gamma-8$ in the mouse brain. Immunoblot and immunofluorescence revealed the highest concentration of $\gamma$-8 in the hippocampus. Immunogold electron microscopy demonstrated dense distribution of $\quad \gamma-8$ on the synaptic and extrasynaptic surface of hippocampal neurons with very low intracellular labeling. Of the neuronal surface, $\gamma-8$ was distributed at the highest level on asymmetrical synapses of pyramidal cells and interneurons, whereas their asymmetrical synapses selectively lacked immunogold labeling. Then, the role of $\gamma-8$ in AMPA receptor expression was pursued in the hippocampus using mutant mice defective in the $\gamma-8$ gene. In the mutant CA1 region, synaptic and extrasynaptic AMPA receptors on dendrites and spines were severely reduced to $35-37 \%$ of control levels, whereas reduction was mild for extrasynaptic receptors on somata (74\%) and no significant decrease was seen for intracellular receptors within spines. In the mutant CA3 region, synaptic AMPA receptors were reduced mildly at asymmetrical synapses in the stratum radiatum (67\% of control level), and showed no significant decrease at mossy fiber-CA3 synapses. Therefore, $\gamma-8$ is abundantly distributed on hippocampal excitatory synapses and extrasynaptic membranes, and plays an important role in increasing the number of synaptic and extrasynaptic AMPA receptors on dendrites and spines, particularly, in the CA1 region. Variable degrees of reduction further suggest that other TARPs may also mediate this function at 
different potencies depending on hippocampal subregions, input sources, and neuronal compartments. 


\section{Introduction}

In the mammalian central nervous system, glutamate mediates most of the fast excitatory synaptic transmission through the $\alpha$-amino-3-hydroxyl-5-isoxazolepropionate (AMPA)-type, kainate-type, and $N$-methyl-D-aspartate (NMDA)-type ionotropic glutamate receptors (Dingledine et al., 1999). AMPA receptors are multimeric channel complexes consisting of GluR1-4 (GluR $\alpha 1-\alpha 4$ in mice), and their subunit combinations determine channel properties, such as current-voltage relationship and $\mathrm{Ca}^{2+}$ permeability (Hollmann et al., 1991; Hume et a l., 1991; Verdoorn et al., 1991; Mosbacher et al., 1994). AMPA receptors mediate basic synaptic transmission, and are crucial for expression of synaptic plasticity. Following activity-dependent $\mathrm{Ca}^{2+}$ influx through NMDA receptors, the number of AMPA receptors undergoes dynamic changes by endocytosis-exocytosis and by lateral movement from extrasynaptic to synaptic sites, which are thought to underlie activity-dependent neural plasticity and developmental synapse maturation (Sheng and Lee, 2001; Malinow and Malenka, 2002; Song and Huganir, 2002; Bredt and Nicoll, 2003).

Functional role of stargazin or $\mathrm{Ca}^{2+}$ channel auxiliary subunit $\gamma-2$ originally arose from the discovery that AMPA receptor-mediated excitatory postsynaptic currents are missing at cerebellar mossy fiber-granule cell synapses, but not at hippocampal synapses, in the ataxic mutant mouse stargazer (stg) (Hashimoto et al., 1999) and in the waggler, an allelic to the stg (Chen et al., 1999). Stargazin and its structurally related $\gamma-3, \gamma-4$, and $\gamma-8$ have been termed the transmembrane AMPA receptor regulatory proteins (TARPs) 
(Tomita et al., 2003), and are now considered as functional auxiliary subunits of AMPA receptors, based on the following observations. When transfected with AMPA receptor subunits, TARPs regulate cell surface delivery (Chen et al., 2000; Tomita et al., 2003), synaptic targeting through interaction with postsynaptic density (PSD)-95 (Chen et al., 2000; Tomita et al., 2003, 2005a), AMPA receptor recycling (Tomita et al., 2004), and AMPA receptor activity by increasing the rate of channel opening (Yamazaki et al., 2004; Tomita et al., 2005b). Each member of TARPs displays distinct regional and cellular expressions in the brain (Tomita et al., 2003; Fukaya et al., 2005). Stargazin is highly expressed in cerebellar granule cells, while $\gamma-8$ is predominant in the telencephalon with the highest level in the hippocampus, suggesting functional involvement of individual TARPs in region- and cell type-dependent manners.

Here we show that $\gamma-8$ is co-expressed with AMPA receptors at asymmetrical synapses and on the extrasynaptic membrane of hippocampal neurons. In $\gamma$-8-knockout (KO) mice, AMPA receptor expression is severely reduced from the synaptic and extrasynaptic membranes of dendrites and spines. These findings suggest that $\gamma-8$ is the major TARP in hippocampal neurons, and plays a key role in increasing the number of synaptic and extrasynaptic AMPA receptors at these neuronal compartments. The impaired AMPA receptor expression is generally consistent with a preceding report by Rouach et al. (2005). However, quantitative differences are also noted between the studies, particularly in estimated reduction of extrasynaptic AMPA receptor expression. AMPA receptors are reduced to similar extents at synaptic and extrasynaptic sites in the present study, whereas they are reduced much more severely at extrasynaptic 
sites than at synaptic sites (Rouach et al., 2005).

\section{Materials and methods}

\section{Animals}

All animal experiments were carried out in accordance with the guidelines laid down

by the animal welfare committees of Niigata University and Hokkaido University. The TARP $\gamma$-8-deficient mouse was produced by homologous recombination using a new ES cell line RENKA, which we developed from the C57BL/6N strain. We first isolated a genomic fragment carrying exons 2-4 of the $\gamma-8$ gene by PCR from C57BL/6 mouse genomic DNA (Fig. 4A). The $1.8 \mathrm{~kb}$ DNA fragment, which carried the 34 bp loxP sequence and Pgk-1 promoter-driven neomycin phosphotransferase gene (neo) flanked by two Flp recognition target (frt) sites (Takeuchi et al. 2002), was inserted into the site 143 bp upstream of the exon 3 . The 34 bp loxP sequence with 26 bp linker sequence was inserted into the site 203 bp downstream of the exon 3. The targeting vector ptvG8-flox contained exon 3 of the $\gamma-8$ gene flanked by loxP sequences, $7.2 \mathrm{~kb}$ upstream and $2.9 \mathrm{~kb}$ downstream genomic sequences, and 4.3 kb pMC1DTpA (Kitayama et al. 2001).

ES cells were cultured on mitomycin C-treated neomycin-resistant fibroblasts in Dulbecco's modified Eagle’s me dium (DMEM, high glucose) (Invitrogen, Carlsbad, CA, USA) supplemented with $17.7 \%$ ES-cell qualified fetal calf serum (Invitrogen), $88.4 \mu \mathrm{M}$ non-essential amino acids (Invitrogen), $884 \mu \mathrm{M}$ Sodium pyruvate (Sigma, St. Louis, MO, USA), 88.4 
$\mu \mathrm{M}$ 2-mercaptoethanol (Sigma), and $884 \mathrm{U} / \mathrm{ml}$ murine leukemia inhibitory factor, ESGRO (Chemicon International, Temecula, CA). Linearized ptvG8-flox was electroporated into RENKA cells, and G-418 (175 $\mu \mathrm{g} / \mathrm{ml}$ ) resistant clones were picked up. Recombinant clones were identified by Southern blot hybridization analysis (Fig. 4B). Recombinant ES cells were injected $\begin{array}{llllll}\text { into } & \text { eight-cell } & \text { stage } & \text { embryos } & \text { of } & \text { CD-1 }\end{array}$ mouse strain. The embryos were cultured to blastocysts and transferred to psudopregnan t CD-1 mouse uterus. Resulting chimeric mice were mated to C57BL/6 mice, and offspring $\left(\gamma-8^{+/ f l o x}\right)$ were further crossed with TLCN-Cre mice (Nakamura et al., 2001; Fuse et al., 2004) to yield heterozygous $\left(\gamma-8^{+/}\right)$mice (Fig. 4C). Homozygous $\gamma$-8-KO and control mice were obtained by crossing heterozygous pairs. Mice were examined at 9 weeks of age for immunohistochemical analysis and 8-11 weeks for immunoblot analysis.

\section{Antibody}

Polyclonal antibodies against the following molecules were used; $\gamma-8$ (raised in the rabbit and guinea pig), pan-AMPA receptor (guinea pig), GluR $\alpha 1$ (GluR1) subunit (rabbit, Shimuta et al., 2001), GluRa2 (GluR2) subunit (rabbit, Shimuta et al., 2001), NMDA receptor GluR $\zeta 1$ (NR1) subunit (C2 cassette, rabbit, Watanabe et al., 1998; C2' cassette, guinea pig, Abe et al., 2004) and GluRe2 (NR2B) subunit (rabbit, Watanabe et al., 1998), vesicular glutamate transporters VGluT1 and VGluT2 (guinea pig, Miyazaki et al., 2003), plasmalemmal glutamate transporter GLAST (guinea pig, Shibata et al., 1997), and actin (rabbit, Chemicon International Inc., CA, USA). 
The $\gamma-8$ and pan-AMPA receptor antibodies were raised in the present study. Nucleotide sequences encoding C-terminal amino acid residues 372-431 (cytoplasmic epitope) of mouse $\gamma-8$ (accession No. AF361350), and amino acid residues 717-754 (LLESTMNEYIEQRKPCDTMKVGGNLDSKGYGIATPKGS， extracellular/luminal epitope) and 727-745 (EQRKPCDTMKVGGNLDSKG, extracellular/luminal) of mouse GluR $\alpha 1$ (X57497, see Supplemental Fig. 1A) were obtained by polymerase chain reaction using single-stranded mouse cDNA library. The longer GluR $\alpha 1$ sequence, which lies between transmembrane segments TM3 and TM4 and upstream to the flip/flop site, was used for antigen, while the shorter one, which is common to all four AMPA receptor subunits and low in homology to other ionotropic glutamate receptor subunits, was used for affinity purification (Supplemental Fig. 1A). After subcloning into pGEM-T Easy plasmid by the TA cloning (Promega, Madison, WI, USA), cDNA fragments were checked by sequencing, excised by restriction enzymes BamHI and EcoRI, and subcloned into pGEX-4T-2 plasmid vector (Amersham Biosciences, Piscataway, NJ, USA). Glutathione S-transferase (GST) fusion proteins were expressed in E. coli and purified using Glutathione-Sepharose 4B (Amersham Biosciences). Fusion proteins were emulsified with Freund's complete or incomplete adjuvant (DIFCO, Detroit, MI, USA), and injected subcutaneously into female rabbits and guinea pigs at intervals of 2 weeks. From antisera, specific antibodies were purified using GST-free polypeptides coupled to Sepharose 4B (Amersham Biosciences). The specificity of $\gamma-8$ antibody was confirmed 
by the absence of immunoblot and immunohistochemical labeling in $\gamma-8-\mathrm{KO}$ mice (Fig. 2A, 2B, 4D). The specificity of pan-AMPA receptor antibody was shown by blank immunoperoxidase staining with antibody preabsorbed with $50 \mu \mathrm{g} / \mathrm{ml}$ of GST fusion protein carrying 727-745 amino acid residues of GluR $\alpha 1$ and also by immunoblot using COS7 cell lysates transfected with AMPA receptor and kainate receptor subunits (Supplemental Fig. 1B-D). Pan-AMPA receptor antibody strongly recognized a single band at $100 \mathrm{kDa}$ of GluR $\alpha 1-\alpha 4$ subunits with a trace of cross-reactivity to kainate receptor GluR $\beta 2$ (or GluR6) subunit.

\section{Histology and immunohistochemistry}

Under deep pentobarbital anesthesia (100 $\mathrm{mg} / \mathrm{kg}$ of body weight, i.p.), mice were perfused transcardially with $4 \%$ paraformaldehyde/0.1M sodium phosphate buffer (PB, pH 7.2) for histology, immunoperoxidase, and immunofluorescence or with 4\% paraformaldehyde/0.1\% glutaraldehyde/0.1M PB for immunoelectron microscopy. Brains of $\gamma-8-\mathrm{KO}$ and control mice were embedded in single paraffin blocks to examine histology and immunoperoxidase using paraffin sections (SM1000R, Leica, Nussloch, Germany). Microslicer sections (VT1000S, Leica) were prepared for immunofluorescence (50 $\mu \mathrm{m}$ in thickness) and for preembedding $(50 \mu \mathrm{m})$ and postembedding $(400 \mu \mathrm{m})$ immunoelectron microscopies.

All immunohistochemical incubations were done at room temperature. For light microscopic immunohistochemistry, primary antibodies were diluted to $1 \mu \mathrm{g} / \mathrm{ml}$ with phosphate-buffered saline (PBS) for immunoperoxidase or PBS
containing
$0.1 \%$
Tween
20
(TPBS)
for 
immunofluorescence. Immunoperoxidase was performed by successive incubation with primary antibodies overnight, biotinylated secondary antibodies for $2 \mathrm{hr}$, and avidin-biotin-peroxidase complex for $1 \mathrm{hr}$, using a Histofine SAB-PO(R) kit (Nichirei Corp., Tokyo, Japan). Immunoreaction was visualized with 3,3'-diaminobenzidine, and photographs were taken by an AX-80 light microscope (Olympus, Tokyo, Japan). For immunofluorescence, microslicer sections were immunoreacted overnight with rabbit $\gamma-8$ antibody singly or in combination with guinea pig antibodies. They were visualized by $2 \mathrm{hr}$ incubation with indocarbocyanine $\quad$ (Cy3)-labeled $\quad$ dgakey (1:200, Jackson ImmunoResearch, West Grove, PA, USA) and/or Alexa488-labeled goat anti-guinea pig antibody (1:200, Molecular Probes, Eugene, OR, USA). After washing three times with TPBS, images were taken with a confocal laser scanning microscope (FV1000, Olympus). All images were obtained by restricting the width of emission wavelength using spectral slit and by adopting the sequential mode of laser scanning, both to minimize the fluorescence crosstalk.

Preembedding silver-enhanced immunogold electron microscopy often yields higher labeling in superficial portions of immunostained sections than deeper portions, because of limited antibody penetration from the section surface. To overcome this problem for quantitative assessment, microslicer sections were permeabilized with $0.02 \%$ saponin for $30 \mathrm{~min}$, and $0.004 \%$ saponin was added to diluent of blocking serum and antibodies. Sections were incubated overnight with primary antibodies and then with anti-rabbit or -guinea pig IgG conjugated with colloidal gold for $2 \mathrm{hr}(1.4 \mathrm{~nm}$ in diameter, Nanogold, 
Nanoprobes Inc., Stony Brook, NY, USA). After silver enhancement (HQ silver, Nanoprobes), sections were treated with $0.5 \%$ osmium tetroxide, stained in block with 2\% uranyl acetate, dehydrated, and embedded in Epon 812. Ultrathin sections were prepared from $<1.5 \mu \mathrm{m}$ from the section surface, mounted on nickel grids, and stained with $2 \%$ uranyl acetate for $10 \mathrm{~min}$.

For postembedding immunogold, slices were cryoprotected with $30 \%$ sucrose in 0.1M PB, and frozen rapidly with liquid propane in a Leica EM CPC unit. Frozen sections were immersed in $0.5 \%$ uranyl acetate in methanol at $-90{ }^{\circ} \mathrm{C}$ in a Leica AFS freeze-substitution unit, infiltrated at $-45{ }^{\circ} \mathrm{C}$ with Lowicryl HM-20 resin (Lowi, Waldkraiburg, Germany), and polymerized with UV light. After etching with saturated sodium-ethanolate solution for 3 sec, ultra-thin sections on nickel grids were treated successively with $1 \%$ human serum albumin (Wako, Osaka, Japan)/0.1\% Tween 20 in Tris-buffered saline (HTBST pH 7.5) for $1 \mathrm{hr}$, primary antibodies (15 $\mu \mathrm{g} / \mathrm{ml}$ for each) in HTBST overnight, and colloidal gold (10 nm)-conjugated anti-rabbit IgG (1:100, British Bio Cell International, Cardiff, UK) in HTBST for 2 hr. Finally, grids were stained with uranyl acetate for 15 min.

Electron micrographs were taken randomly by an H7100 electron microscope (Hitachi, Tokyo, Japan). For quantitative analysis, the number of metal particles and the length of plasma membrane were measured on electron micrographs, using an IPLab software (Nippon Roper, Tokyo, Japan). Statistical significance was assessed by Student's $t$-test.

\section{Immunoblot}


For quantitative Western blot analysis, three or five brains from each genotype were pooled for one experiment. The brain tissues were homogenized in 10 volumes of sucrose buffer $(0.32 \mathrm{M}$ sucrose, $5 \mathrm{mM}$ EDTA, 0.5 $\mathrm{mM}$ phenylmethylsulfonlfluoride, $2 \mu \mathrm{M}$ leupeptin, and $1 \mu \mathrm{m}$ pepstatin) and centrifuged at $700 \mathrm{x} \mathrm{g}$ for $10 \mathrm{~min}$ to obtain the postnuclear fraction (homogenates, S1 in Fig. 4). The cell fractionation was carried out as described previously (Carlin et al., 1980; Abe et al., 2004). To compare protein solubility, the synaptosomal fraction was treated with various concentration of Triton X-100 for 15 min on ice and then centrifuged at $81,600 \mathrm{x} \mathrm{g}$ for $1 \mathrm{hr}$. The resultant pellets were resuspended with 40 $\mathrm{mM}$ Tris-Cl pH8.0 and 1\% sodium dodecyl sulfate (SDS). The determination of protein concentrations mas by the method of Lowry. SDS-polyacrylamide electrophoresis and Western blot were carried out according to Abe et al. (2004). Signal intensities of immunoreaction were determined digitally using the densitometry function of NIH image (available from the U.S. National Institutes of Health) and normalized with loaded proteins. Statistical analysis was performed using Student's $t$-test

\section{Results}

\section{Immunoblot analysis of TARP $\gamma-8$}

By immunoblot using $\gamma$-8-specific antibody and pan-AMPA receptor antibody, regional distributions of $\gamma-8$ and AMPA receptors were comparatively examined biochemically. In homogenates from seven brain regions of adult C57BL/6 mice, we found that the levels of $\gamma-8$ and AMPA receptors were both highest 
in the hippocampus (Fig. 1A). Densitometric measurement $\begin{array}{lllll}\text { demonstrated that } & \text { hippocampal content } & \gamma-8\end{array}$ was overwhelming among brain regions examined (Fig. 1B). On the other hand, regional differences of AMPA receptor distribution were less variable compared to $\gamma$-8 (Fig. 1B).

Protein solubility of $\gamma-8$ was compared with AMPA receptors, NMDA receptor subunit GluRe2 (NR2B), and their interacting scaffold protein PSD-95. The synaptosomal fraction was prepared as starting samples by purification with the sucrose density gradient fractionation, and detergent-soluble components were eliminated to obtain the postsynaptic density (PSD) fraction by step-wise increase of Triton X-100 concentrations (Fig. 1C, D). Relative contents of $\gamma-8$ were first decreased to half the initial level (i.e., synaptosomal fraction or $0 \%$ Triton $\mathrm{X}-100)$ at low detergent concentration (0.125\% Triton X-100), and then slightly increased with the increase of detergent $\begin{array}{llllll}\text { concentrations (PSD fraction } & \text { or } & 0.5 \% & \text { Triton } & \mathrm{X}-100) \text {. }\end{array}$ On the other hand, from the synaptosomal to the PSD fraction, relative contents of AMP A receptors were almost constant or slightly increased, while GluRe2 subunit and PSD-95 displayed progressive condensation up to 4- or 12-folds, respectively. Therefore, hippocampal $\gamma-8$ is composed of detergent-sensitive and -insensitive components; the former component is particularly large for $\gamma-8$ as well as AMPA receptors, when compared to NMDA receptors and PSD-95. 
In microslicer sections of the adult mouse brain, immunofluorescence for $\gamma$-8 intensely labeled the telencephalon especially the hippocampus (Fig. 2A, C). This immunostaining was specific, because labeling was not seen in the $\gamma-8-\mathrm{KO}$ brain (Fig. 2B). In the hippocampus, intense signals were observed on the surface of neuronal somata as well as on dendritic shafts that often yielded cylindrical and circular patterns of immunostaining by optical sectioning with a confocal microscope (Fig. 2D-G). Neuropils between dendritic shafts were also filled with intense fignals for $\gamma-8$. $\quad$ Furthermore, weak particulate labeling was occasionally seen inside perikarya and dendritic shafts. By double immunofluorescence, $\gamma$-8-positive structures in the neuropil were apposed close to both glutamatergic terminal marker VGluT1 (Fig. 2E, F) and astroglial marker glutamate transporter GLAST (Fig. 2G), but appeared unlikely to overlap with either of the two.

Then, double immunofluorescence was performed with pan-AMPA receptor antibody (Fig. 2H-K). In contrast to characteristic hippocampal immunostaining for $\gamma-8$ (Fig. 2H1), signals for AMPA receptors were very low (Fig. 2H2); weak signals were visible in perikarya, dendrites, and neuropils, only when gain levels of a confocal microscope were raised (data not shown). Because immunohistochemical detection of PSD molecules is often hindered because of extensive protein-protein interaction, we employed pepsin pretreatment, which has been shown to effectively visualize PSD molecules at the light microscopic level when applied to formalin-fixed brain sections (Watanabe et al., 1998; Fukaya and Watanabe, 2000; Yamada et al., 2001). Incubation with $1 \mathrm{mg} / \mathrm{ml}$ of pepsin for $1 \mathrm{~min}$ at $37^{\circ} \mathrm{C}$ greatly intensified immunostaining for AMPA receptors, 
but not for $\gamma-8$ (Fig. 2I). After 3 min of pepsin incubation, the intensity of immunofluorescence was further augmented for both $\gamma-8$ and AMPA receptors (Fig. 2J). As a result, extensive overlap of the two molecules was displayed on the somatodendritic surface and in the neuropil (Fig. 2K).

To determine subcellular distribution of $\gamma-8$, we employed immunogold electron microscopy in the CA1 (Fig. 3A-F) and CA3 (Fig. 3G, H) regions. By preembedding silver-enhanced immunogold method, metal particles for $\gamma-8$ were heavily deposited along the cytoplasmic side of the extrasynaptic membrane on somata, dendritic shafts, and spines (Fig. 3A-C). Occasionally, intracellular labeling was found around the endoplasmic reticulum (ER). No significant labeling was seen in the synaptic membrane, axons, and terminals (Fig. 3C). Conversely, postembedding immunogold revealed high levels of synaptic labeling (Fig. 3D, F-H). Gold particles for $\gamma-8$ were accumulated on the postsynaptic membrane of asymmetrical synapses on spines (Fig. 3D, G, H) and dendritic shafts (Fig. 3F). Extrasynaptic membranes of spines and dendrites were also labeled by postembedding method (arrows in Fig. 3D, G), but the extrasynaptic labeling was apparently lower in levels than synaptic labeling. The specificity of preembedding (data not shown) and postembedding immunogold labeling (Fig. 3E) was verified by the lack of significant labeling in $\gamma-8-\mathrm{KO}$ mice.

Therefore, conventional preembedding methods readily detect $\gamma$-8 at extrasynaptic and intracellular sites, whereas pepsin pretreatment and postembedding method can effectively detect synaptic $\gamma-8$. 


\section{Quantitative assessment of synaptic, extrasynaptic, and intracellular $\gamma-8$}

The distribution of $\gamma-8$ at synaptic, extrasynaptic, and intracellular sites were quantitatively evaluated from immunogold electron micrographs (Fig. 3I-L). By postembedding method, most particles on spines in the CA1 stratum radiatum were associated with the cell membrane (96.4\%), as judged by $<30 \mathrm{~nm}$ from the cell membrane to the center of gold particles, while the rest were judged as intracellular labeling (>30 nm, 3.6\%) (Fig. 3I). Of the cell membrane-associated gold particles on spines, labeling density was 3.4-fold higher for synaptic membrane than for extrasynaptic membrane (Fig. 3J). Such a high synaptic labeling was also observed at other asymmetrical synapses in the CA1 and CA3 regions, whereas it was very low at symmetrical synapses (Fig. 3K), indicating selective expression at excitatory synapses. Therefore, $\gamma-8$ is highest on the synaptic membrane of various excitatory synapses, and also distributed on the extrasynaptic membrane. Levels of extrasynaptic labeling in different somatodendritic compartments were further compared by preembedding immunogold labeling. In CA1 pyramidal cells, we found a higher density of extrasynaptic labeling in dendritic shafts than in spines and somata (Fig. 3L).

\section{Selective reduction of hippocampal AMPA receptors in $\gamma-8-\mathrm{KO}$ mice}

To address the role of $\gamma$-8 for hippocampal AMPA receptor expression, we produced $\gamma-8-\mathrm{KO}$ mice by homologous recombination using a newly developed ES cell line derived from the C57BL/6N strain (Fig. 4A-C, see Materials and Methods). From heterozygous pairs, $\gamma$-8-KO mice were born in the Mendelian ratio, and the absence of $\gamma-8$ protein was confirmed in the brain of $\gamma-8-\mathrm{KO}$ mice (Fig. 4D). 
By loading appropriate amounts of homogenates and fractionated protein samples, hippocampal contents of AMPA receptors, GluRe2, and PSD-95 were compared between control and $\gamma-8-\mathrm{KO}$ mice (Fig. 4D, E). In $\gamma-8-\mathrm{KO}$ mice, AMPA receptors were significantly reduced to half the level of control mice in the homogenate (S1, $46.0 \pm 6.8 \%$ (s.e.m.), $p<0.01, t$-test, $\mathrm{n}=4$ for both mice), crude synaptosomal fraction (P2, $52.0 \pm 2.6 \%, p<0.01, \mathrm{n}=5)$, microsomal fraction (P3, $59.0 \pm 4.7 \%, p<0.01, \mathrm{n}=5)$, and PSD fraction $(35.0 \pm 1.5 \%, p<0.01, \mathrm{n}=3)$. In contrast, no significant reduction was observed for GluRe2 or PSD-95 in the homogenate and any fractions. No gross defects were found in the size, proportion, or histology of $\gamma$-8-KO brain, including the hippocampus (Fig. 4F-H).

Changes in immunohistochemical distribution of AMPA receptors were examined in the hippocampus (Fig. 5-7). First, we light compared microscopic distribution of AMPA receptors by employing pepsin pretreatment for 3 min (Fig. 5A, B, G-L). As compared to control mice, immunofluorescence intensity for AMPA receptors was considerably lowered in $\gamma$-8-KO hippocampus (Fig. 5A, B). This reduction was selective to AMPA receptors, because no differences were noted for NMDA receptor subunit GluRל1 (NR1) (Fig. 5C, D), GluRe2 (data not shown), PSD-95 (data not shown), and glutamatergic terminal marker VGluT1 (Fig. 5E, F). At higher magnifications, reduction was marked in most dendritic layers of the CA1 (Fig. 5G, J), CA3 (Fig. 5H, K), and dentate gyrus (Fig. 5I, L). Exceptionally, reduction was very mild in the stratum lucidum of the CA3 region (Fig. 5H, K), in which mossy fibers terminate to form glutamatergic synapses with CA3 pyramidal cells and interneurons (Hamlyn, 1962; Acsady et al., 
1998). No significant changes were discerned for perikaryal staining of pyramidal

$\begin{array}{llll}\text { cells } & \text { and granule cells }\end{array}$

(Fig.

5G-L). These results demonstrate that AMPA receptors are selectively reduced in $\gamma$-8-KO hippocampus mainly due to the loss of AMPA receptors from dendrites.

\section{Quantitative assessment of synaptic AMPA receptors in $\gamma-8-\mathrm{KO}$ mice}

Changes in synaptic AMPA receptors were assessed by postembedding immunogold (Fig. 6). Synaptic labeling was reduced to variable degrees at axo-spinous asymmetrical synapses in $\gamma$-8-KO hippocampus. The most severe reduction was noted in the CA1 stratum radiatum (Fig. 6A, B), where the number of immunogold per synaptic profile was significantly reduced to $35 \%$ of control level in $\gamma-8-\mathrm{KO}$ mice (3.84 \pm 0.41 (s.e.m.) vs. $1.34 \pm 0.30$ for control and $\gamma$-8-KO, respectively, $p<0.01, t$-test, $\mathrm{n}=96$ synapses for control, $\mathrm{n}=78$ synapses for $\gamma-8-\mathrm{KO}$, Fig. 6G). In the CA3 region, the density of synaptic labeling was significantly reduced to $67 \%$ in the stratum radiatum $(3.76 \pm$ 0.51 vs. $2.50 \pm 0.43, p<0.05, n=35$ synapses for control, $n=42$ synapses for $\gamma-8-K O$, Fig. 6I). In the stratum lucidum, however, reduction was very mild (83\%) at mossy fiber-CA3 synapses, showing no significant difference $(4.75 \pm 0.44$ vs. $3.95 \pm$ 0.47, $p>0.05, \mathrm{n}=42$ synapses for control, $\mathrm{n}=42$ synapses for $\gamma-8-K O$, Fig. 6E, F, J). Synaptic labeling for GluR $\zeta 1$ subunit, as examined using a mixture of C2 and C2' cassette antibodies (Abe et al., 2004), was comparable between control and $\gamma$-8-KO mice $(3.93 \pm 0.28$ vs. $4.15 \pm 0.28, p>0.05, n=83$ synapses for control, $n=84$ synapses for $\gamma$-8-KO, Fig. 6C, D, H). Thus, despite high expression of $\gamma-8$ at various hippocampal

synapses

(Fig. $3 \mathrm{~K}$, 
synaptic AMPA receptors were differentially affected in the absence of $\gamma-8$, depending on hippocampal regions and layers.

\section{Quantitative assessment of extrasynaptic and intracellular AMPA receptors in $\gamma-8-K O$ mice}

Because pan-AMPA receptor antibody binds to extracellular epitopes, it was often difficult to distinguish cellular origin of immunogolds, when they fell between two cell membranes apposing close to each other. To overcome this problem, we used to compare extrasynaptic AMPA receptors, GluR $\alpha 1$ (or GluR1)-specific antibody that recognizes intracellular epitopes of the subunit. However, when applying the GluR $\alpha 1$ antibody to postembedding immunogold method, the sensitivity was less than half of that obtained with pan-AMPA receptor antibody. In control mice, the density of synaptic and extrasynaptic GluRa1 labeling was 4.32 and 0.69 particles, respectively, per 1 $\mu \mathrm{m}$ of the cell membrane in CA1 pyramidal cells. Because labeling density was further reduced in $\gamma-8-\mathrm{KO}$ mice; in particular, extrasynaptic labeling became much less and appeared indistinguishable from the background level. Therefore, changes in extrasynaptic as well as intracellular AMPA receptors were assessed by preembedding silver-enhanced immunogold using GluRa1-specific antibody (Fig. 7).

Light microscopic observation on silver-enhanced immunogold labeling revealed that diffuse labeling in dendritic layers was substantially decreased in $\gamma-8-\mathrm{KO}$ hippocampus, whereas no marked changes were appreciable for somatic labeling (Fig. 7A, B), 
similarly to the results by immunofluorescence (Fig. 5G-L). By electron microscopy, silver particles for GluR $\alpha 1$ subunit in the CA1 stratum radiatum were associated with extrasynaptic membrane or distributed intracellularly in both genotypes of mice (Fig. 7C-H). By counting the number of silver particles per spine, cell membrane-associated labeling for GluR $\alpha 1$ subunit was significantly reduced in $\gamma-8-\mathrm{KO}$ mice to $47 \%$ of control level $(0.38 \pm 0.02$ (s.e.m.) vs. $0.18 \pm 0.02$ for control and $\gamma-8-K O$, respectively, $p<0.01, n=265$ spines for control, $n=250$ for $\gamma-8-K O$ ), whereas intracellular labeling was almost comparable (83\%; $0.12 \pm 0.01$ vs. $0.10 \pm$ 0.01, $p>0.05$, Fig. 7I). Changes in extrasynaptic GluR $\alpha 1$ labeling were further compared among respective somatodendritic compartments. In control mice, the density of extrasynaptic labeling was higher in dendritic shafts than in spines and somata (Fig. 7J), as is the case for $\gamma-8$ (Fig. 3L). In $\gamma-8-\mathrm{KO}$ mice, substantial reduction was seen in extrasynaptic spine membrane (38\% of control level; $0.71 \pm 0.09$ (s.e.m.) vs. $0.26 \pm$ 0.03 for control and $\gamma-8-\mathrm{KO}$, respectively, $p<0.01$ ) and extrasynaptic dendritic membrane ( $36 \%$; $1.32 \pm 0.13$ vs. $0.48 \pm 0.03, p<0.01)$, whereas reduction was mild in extrasynaptic somatic membrane (73\%; $0.69 \pm \quad 0.07 \quad$ vs. $0.41 \pm$ 0.09, $p>0.05$ ). Since these scores were much higher than the background level, as determined from presynaptic terminal membrane (Fig. 7J), the extrasynaptic and intracellular labeling was considered to be specific. Therefore, in CA1 pyramidal cells of $\gamma-8-\mathrm{KO}$ mice, extrasynaptic GluR $\alpha 1$ labeling in spines and dendrites are reduced severely and similarly to synaptic AMPA receptors (Fig. 6G). 


\section{DISCUSSION}

In the present study, we aimed at clarifying subcellular distribution of $\gamma-8$ in hippocampal neurons, and pursuing its role in AMPA receptor expression. The phenotypic alterations we observed in our $\gamma-8-\mathrm{KO}$ mice are qualitatively consistent in many respects with those in the preceding study (Rouach et al., 2005), but several quantitative differences are also observed as discussed later.

\section{$\gamma-8$ is the major TARP of hippocampal AMPA receptors}

The concentrations of $\gamma-8$ and AMPA receptors were both highest in the hippocampus (Fig. 1A, B), where similar biochemical and immunohistochemical features were noted. First, spatial patterns of hippocampal immunolabeling for $\gamma-8$ and AMPA receptors very resembled to each other at both the histological (Fig. 2I, J) and cytological (Fig. 2K) levels. Intense signals were detected in dendritic layers, particularly in the stratum oriens and stratum radiatum of the CA1 region, and distributed along somatodendritic surface and in the neuropil. Second, postembedding immunogold technique was needed to reveal synaptic $\gamma-8$ (Fig. 3D, F-H), whereas those in the extrasynaptic and intracellular sites were readily detected by conventional preembedding immunohistochemistry (Fig. 3A-C). Such distinctive labeling properties by preand postembedding methods are essentially the same as in AMPA receptors (Baude et al., 1995; Bernard et al., 1997; Fig. 6, 7 in the present study). Postembedding immunogold and pepsin pretreatment may help the exposure of synaptic 
$\gamma-8$ and AMPA receptors and eventually facilitates immunohistochemical detection (Ottersen and Landsend, 1997; Watanabe et al., 1998). Third, quantitative assessment by pre- and postembedding immunogold analyses clarified that the density of $\gamma-8$ was highest on the synaptic membrane of asymmetrical synapses (Fig. 3J, K). $\gamma-8$ was also distributed at substantial densities on the extrasynaptic membrane, where higher density was found in dendrites than in spines and somata (Fig. 3J, L). These distribution properties are essentially true for AMPA receptors (Baude et al., 1995; Nusser et al., 1998a; Fig. 6, 7). Fourth, $\gamma-8$ and AMPA receptors in the synaptosomal fraction contain much larger amounts of detergent soluble component (Fig. 1C, D). Close biochemical nature between $\gamma-8$ and AMPA receptors is also indicated by their similar distribution in fractions of the sucrose density gradient of Triton X-100-treated synaptic plasma membrane-enriched samples (Inamura et al., 2006). Furthermore, it has been demonstrated that $\gamma$-8 forms co-immunoprecipitable complex with AMPA receptors (Sharp et al., 2001; Tomita et al., 2003). Taken altogether, these results suggest that $\gamma-8$ is the major TARP of hippocampal AMPA receptors.

Different from our finding on the fourth point, it has been reported previously that four TARPs in the synaptosomal fraction, including $\gamma-8$, are resistant to extraction with $0.5 \%$ Triton $\mathrm{X}-100$ (Fig. 6A in Tomita et al.,

2003). The reason for the discrepancy remains uncertain. However, remarkable and prog ressive condensation of NMDA receptor GluRe2 subunit and PSD-95 in preparation from the synaptosomal to the PSD fraction contrasted 
sharply with nearly constant levels of $\gamma-8$ and AMPA receptors (Fig. 1C, D), suggesting that the latter are more susceptible to solubilization with detergents than the former.

\section{Abundant extrasynaptic expression and scarce intracellular distribution of $\gamma-8$}

Despite aforementioned similarities, we also found different features in expression patterns between AMPA receptors and $\gamma$-8. In spines of control mice, $\gamma-8$ showed a higher percentage of extrasynaptic labeling in the total surface labeling (23\%, Fig. 3J) than AMPA receptors (14\%, calculated from postembedding immunogold labeling for GluR $\alpha 1$ subunit). The abundant extrasynaptic expression of $\gamma-8$ may account, at least in part, for its better visibility than AMPA receptors by immunofluorescence without protease pretr eatment (Fig. 2H), and also for its larger initial loss during preparation of the PSD fraction than AMPA receptors (Fig. 1C, D). The wide synaptic and extrasynaptic distribution of $\gamma-8$ in the hippocampus is consistent with recent results from SDS-digested freeze-fracture replica labeling (Inamura et al., 2006). In contrast, the percentage of intracellular labeling in the total spine labeling was very low (3.6\%, Fig. 3I). The scarcity of intracellular pool for $\gamma-8$ relative to that for AMPA receptors (24\%, Fig. 7I) seems relevant to the finding by Tomita et al. (2004); upon binding to glutamate, AMPA receptors dissociate from TARPs to be internalized, while TARPs remain on the cell membrane (Tomita et al., 2004). 


\section{Severe deficits of surface AMPA receptors on spines and dendrites, but not somata, in $\gamma$-8-KỌCA1 pyramidal cells}

In CA1 pyramidal cells of $\gamma$-8-KO hippocampus, synaptic AMPA receptor labeling was reduced to 35\% of control level (Fig. 6G). This severe reduction is consistent with the result by Rouach et al. (2005) (33\% of control level). In the present study, similar degrees of reduction were found for extrasynaptic GluR $\alpha 1$ labeling in spines (37\%) and dendritic shafts (36\%) of pyramidal cells (Fig. 7J). Thus, the ablation of $\gamma-8$ results in 3-fold decrease of synaptic and extrasynaptic AMPA receptors on spines and dendrites in CA1 pyramidal cells. This concomitant reduction appears to be explained the two-step mechanism for AMPA receptor expression by TARPs, in which interaction with the cytoplasmic tail of TARPs increases surface AMPA receptors, and the binding of TARPs with PSD-95 targets them to synapses (El-Husseini et al., 2000; Chen et al., 2000; Chetkovich et al., 2002; Schnell et al., 2002; Bredt and Nicoll, 2003).

Despite lower receptor density on the extrasynaptic surface than at the synaptic site, the total extrasynaptic AMPA receptors should outnumber the total synaptic AMPA receptors, taking into account the vast area of the extrasynaptic membrane on neuronal surface. Extrasynaptic receptors are thought to operate as a detector of extracellular levels of neurotransmitters diffusing out of the synaptic cleft, and to control the excitability of a given neuronal portion or a whole neuron (Nusser et al., 1998b; Dzubay and Jahr, 1999; Sem'yanov, 2005). Importantly, $\gamma-8$ is essential for long-term potentiation at CA1 synapses (Rouach et al., 2005). Based on these results, functional role of $\gamma-8$ can be depicted as follows. $\gamma-8$ 
contributes to steady-state synaptic transmission and extrasynaptic sensing of neural activities by increasing the surface AMPA receptors, and is also involved in dynamic-state mobilization of AMPA receptors to the synaptic site to express synaptic plasticity (Passafaro et al., 2001; Choquet and Triller, 2003; Ashby et al., 2004; Groc et al., 2004; Gardner et al., 2005).

In contrast, no significant reduction was seen for extrasynaptic AMPA receptors in CA1 pyramidal cell somata of $\gamma-8-\mathrm{KO}$ mice (Fig. 7J), despite high levels of $\gamma-8$ on the somatic surface (Fig. 3L). It has been reported that a large intracellular pool of AMPA receptors rapidly exchanges with $\begin{array}{llll}\text { surface } & \text { receptors neuronal somata, }\end{array}$ and these newly inserted receptors travel laterally to dendrites and spines on the timescale of seconds (Adesnik et al., 2005). Our finding raises the possibilities that $\gamma-8$ is also important for this fast lateral movement of AMPA receptors from somata to dendrites and spines, while it might play a minor role in surface insertion of intracellular AMPA receptors at the soma.

\section{Differential effects of $\gamma-8$ among hippocampal subregions}

Compared to the severe loss at CA1 synapses, reduction of synaptic AMPA receptors was modest at CA3 synapses in the stratum radiatum (67\%, Fig. 6I), and no significant decrease was observed at mossy fiber-CA3 synapses (Fig. 6J). The differential reduction revealed by immunoelectron microscopy was largely parallel with reduced immunofluorescence intensity in given 
subregions of $\gamma-8-\mathrm{KO}$ mice (Fig. 5G-L). Four TARPs are known to exhibit differential regional and cellular expression within the hippocampus. In contrast to higher expression of $\gamma-8$ and $\gamma-3$ in the CA1 region, stargazin $(\gamma-2)$ is expressed at higher levels in the CA3 and dentate gyrus than the CA1, although cell types expressing $\gamma$-2 or $\gamma-3$ remain uncertain (Tomita et al., 2003; Fukaya et al., 2005). Thus, it can be assumed that multiple TARPs cooperate for surface expression and synaptic targeting of AMPA receptors. Differences in relative amounts of individual TARPs in given hippocampal subregions and synapses might lead, at least partly, to differential reduction of AMPA receptor expression in $\gamma$-8-KO mice.

\section{Differences between the present and preceding studies}

Between the present and preceding (Rouach et al., 2005) studies, several quantitative differences exist in estimated loss of AMPA receptors in $\gamma-8-\mathrm{KO}$ mice. First, reduction of contents in hippocampal homogenates was much milder in our study $(46 \%$ of control level) than in the previous study (15\%). Our $\gamma-8$-KO mice have a pure C57BL/6 background, whereas the $\gamma-8-\mathrm{KO}$ mice used by Rouach et al. were produced by backcrossing to C57BL/6 mice. The different genetic backgrounds might differentially affect expression levels of four TARPs in wild-type control mice or compensatory expression of other TARPs in $\gamma-8-\mathrm{KO}$ mice.

Second, AMPA receptor expression is reduced to similar degrees at both synaptic and extrasynaptic sites in our study. In the study by Rouach et al. (2005), extrasynaptic immunogold labeling is reduced much more severely (5\% of control level) than $\begin{array}{llll}\text { synaptic } \quad \text { (33\%), } & \text { abeling }\end{array}$ 
extrasynaptic AMPA receptor-mediated responses (10\% of control level) is also severer than that of synaptic ones (70\%). From the first and second differences, it can be assumed that when AMPA receptors are reduced mildly to modestly, like in our mouse model, remaining AMPA receptors are partitioned into the synaptic and extrasynaptic membranes at comparable densities,. However, as is the model by Rouach et al. (2005), further receptor loss might cause preferential depletion from extrasynaptic and intracellular compartments, to which anchoring or scaffolding molecules are poorly provided as compared to the synaptic compartment (Fukaya and Watanabe, 2000). Alternatively, employment of different immungold methods with different detection sensitivities, i.e., preembedding immunogold in our study and postembedding immunogold by Rouach et al., (2005), could also affect the estimation of reduced extrasynaptic AMPA receptors.

Third, our finding that AMPA receptor expression is reduced more severely at CA1 synapses than at mossy fiber-CA3 synapses, is contrary to the order of functional AMPA receptor impairment by Rouach et al. (2005). Our current understanding is that TARPs regulate both trafficking and gating of AMPA receptors. In addition to the enhancement for AMPA receptor expression (Chen et al., 2000; Chetkovich et al., 2002), interaction of AMPA receptors with TARPs greatly augments channel opening by slowing channel deactivation and desensitization, but the potencies are different among TARPs (Yamazaki et al., 2004; Tomita et al., 2005b). Therefore, the apparent discrepancy between AMPA receptor expression and function could be attributable to differential contributions of individual TARPs to receptor trafficking and gating. 
Fourth, in $\gamma$-8-KO pyramidal cells, our immunofluorescence (Fig. 5) and immunogold (Fig. 7A, B) detected no significant increase of perikaryal staining for AMPA receptors, whereas immunoperoxidase staining by Rouach et al. (2005) visualized augmented perikaryal staining. Clearly, this is not a qualitative difference between the studies, but rather this is due to different sensitivity between immunofluorescence/immunogold and immunoperoxidase, because our immunoperoxidase examination confirmed augmented perikaryal staining using pan-AMPA receptor, GluR $\alpha 1$, and GluR $\alpha 2$ antibodies (Supplemental Fig. 2). Thus, both studies are consistent in that AMPA receptors are decreased from dendrites and spines and are redistributed to perikarya, presumably, for degradation in the perikaryal ER (Vandenberghe et al., 2005). It should be mentioned that this redistribution of hippocampal AMPA receptors is fairly mild when compared with that of hippocampal NMDA receptors; in the absence of NR1 (GluR $\zeta 1$ ) subunit, striking perikaryal accumulation of NR2 (GluRe) subunits is visible by both immunofluorescence and immunoperoxidase (Fukaya et al., 2003). This suggests that other TARPs may be also involved in intracellular trafficking of AMPA receptors in hippocampal neurons.

Through the present study, we conclude that $\gamma-8$ is the major TARP in hippocampal neurons, playing an important role in increasing the number of synaptic and extrasynaptic AMPA receptors in dendrites and spines. 


\section{Acknowledgments}

This investigation was supported in part by Grant-in-Aids for Scientific Research (B) $\begin{array}{llll}\text { and } & \text { for } & \text { Scientific } & \text { Research }\end{array}$ Priority Areas from the Ministry of Education, Culture, Sports, Science, and Technology, Japan, also by Uehara Memorial Foundation. 

Abbreviations
AMPA $\quad \alpha$-amino-3-hydroxyl-5-isoxazolepropionate
CA cornu ammonis
Cy3 indocarbocyanine
ER endoplasmic reticulum
GST glutathione $S$-transferase
HTBST $1 \%$ human serum albumin/0.1\% Tween 20 in Tris-buffered
saline
KO knockout
NMDA $\quad N$-methyl-D-aspartate
PB sodium phosphate buffer
PBS phosphate-buffered saline
PSD postsynaptic density
SDS sodium dodecyl sulfate
TARP transmembrane AMPA receptor regulatory protein 


\section{References}

Abe, M., Fukaya, M., Yagi, T., Mishina, M., Watanabe, M. \& Sakimura, K. (2004) NMDA receptor GluRe/NR2 subunits are essential for postsynaptic localization and protein stability of GluR $\zeta 1 / N R 1$ subunit. J. Neurosci., 24, 7292-7304.

Acsady, L., Kamondi, A., Sik, A., Freund, T. \& Buzsaki, G. (1998) GABAergic cells are the major postsynaptic targets of mossy fibers in the rat hippocampus. $J$. Neurosci., 18, 3386-3403.

Adesnik, H., Nicoll, R.A. \& England, P.M. (2005) Photoinactivation of native AMPA receptors reveals their real-time trafficking. Neuron, 48, 977-985.

Ashby, M.C., De La Rue, S.A., Ralph, G.S., Uney, J., Collingridge, G.L. \& Henley, J.M. (2004) Removal of AMPA receptors (AMPARs) from synapses is preceded by transient endocytosis of extrasynaptic AMPARs. J. Neurosci., 24, 5172-5176.

Baude, A., Nusser, Z., Molnar, E., McIlhinney, R.A. \& Somogyi, P. (1995) High-resolution immunogold localization of AMPA type glutamate receptor subunits at synaptic and non-synaptic sites in rat hippocampus. Neuroscience, 69, 1031-1055.

Bernard, V., Somogyi, P. \& Bolam, J.P. (1997) Cellular, subcellular, and subsynaptic distribution of AMPA-type glutamate receptor subunits in the neostriatum of the rat. $J$. Neurosci., 17, 819-833. 
Bredt, D.S. \& Nicoll, R.A. (2003) AMPA receptor trafficking at excitatory synapses. Neuron, 40, 361-379.

Carlin, R.K., Grab, D.J., Cohen, R.S. \& Siekevitz, P. (1980) Isolation and characterization of postsynaptic densities from various brain regions: enrichment of different types of postsynaptic densities. J. Cell Biol., 86, 831-145.

Chen, L., Bao, S., Qiao, X.J. \& Thompson, R.F. (1999) Impaired cerebellar synapse maturation in waggler, a mutant mouse with a disrupted neural calcium channel $\gamma$ subunit. Proc. Natl. Acad. Sci. USA, 96, 12132-12137.

Chen, L., Chetkovich, D.M., Petralia, R.S., Sweeney, N.T., Kawasaki, Y., $\begin{array}{lllll}\text { Wenthold, } & \text { R.J., } & \text { Bredt, } & \text { D.S. } & \text { Nicoll, }\end{array}$ (2000) Stargazin regulates synaptic targeting of AMPA receptors by two distinct mechanisms. Nature, 408, 936-943.

Chetkovich, D.M., Chen, L., Stocker, T.J., Nicoll, R.A. \& Bredt, D.S. (2002) Phosphorylation of the postsynaptic density-95 (PSD-95)/discs large/zona occludens-1 binding site of stargazin regulates binding to PSD-95 and synaptic targeting of AMPA receptors. J. Neurosci., 22, 5791-5796. 
Choquet, D. \& Triller, A. (2003 The role of receptor diffusion in the organization of the postsynaptic membrane. Nat. Rev. Neurosci., 4, 251-265.

Dingledine, R., Borges, K., Bowie, D., Traynelis, S.F. (1999) The glutamate receptor ion channels. Pharmacol. Rev., 51, 7-61.

Dzubay, J.A. \& Jahr, C.E. (1999) The concentration of synaptically released glutamate outside of the climbing fiber-Purkinje cell synaptic cleft. J. Neurosci., 19, $5265-5274$

El-Husseini, A.E., Schnell, E., Chetkovich, D.M., Nicoll, R.A. \& Bredt, D.S. (2000) PSD-95 involvement in maturation of excitatory synapses. Science, 290, 1364-1368.

Fukaya, M. \& Watanabe, M. (2000) Improved immunohistochemical detection of postsynaptically located PSD-95/SAP90 protein family by protease section pretreatment: a study in the adult mouse brain. J. Comp. Neurol., 426, 572-586.

Fukaya, M., Yamazaki, M., Sakimura, K. \& Watanabe, M. (2005) Spatial diversity in gene expression for VDCC $\gamma$ subunit family in developing and adult mouse brains. Neurosci. Res., 53, 376-383.

Fuse, T., Kanai, Y., Kanai-Azuma, M., Suzuki, M., Nakamura, K., Mori, H., Hayashi, Y. \& Mishina, M. (2004) Conditional activation of RhoA 
suppresses

$$
\text { the epithelial }
$$

to

mesenchymal

transition

at the primitive streak during mouse gastrulation. Biochem. Biophys. Res. Commun., 318, 665-672.

Gardner, S.M., Takamiya, K., Xia, J., Suh, J.G., Johnson, R., Yu, S. \& Huganir, R.L. (2005) Calcium-permeable AMPA receptor plasticity is mediated by subunit-specific interactions with PICK1 and NSF. Neuron, 45, 903-915

Groc, L., Heine, M., Cognet, L., Brickley, K., Stephenson, F.A., Lounis, B. \& Choquet, D. (2004) Differential activity-dependent regulation of the lateral mobilities of AMPA and NMDA receptors. Nat. Neurosci., 7, 695-696.

Hamlyn,

L.H.

(1962) The fine structure of the mossy fibre endings in the hippocampus of the rabbit. $J$. Anat., 96, 112-120.

Hashimoto, K., Fukaya, M., Qiao, X., Sakimura, K., Watanabe, M. \& Kano, M. (1999) Impairment of AMPA receptor function in cerebellar granule cells of ataxic mutant mouse Stargazer. J. Neurosci., 19, 6027-6036.

Hollmann, $\quad$ M., $\quad$ Hartley, $\quad$ M. $\quad$ \& $\quad$ Heinemann, S. (1991) $\mathrm{Ca}^{2+}$ permeability of KA-AMPA-gated glutamate receptor channels depends on subunit composition. Science, 252, 851-853. 
Hume, R.I., Dingledine, R. \& Heinemann, S.F. (1991) Identification of a site in glutamate receptor subunits that controls calcium permeability. Science, 253, 1028-1031.

Inamura, M., Itakura, M., Okamoto, H., Hoka, S., Mizoguchi, A., Fukazawa, Y., Shigemoto, R., Yamamori, S. \& Takahashi, M. (2006) Differential localization and regulation of stargazin-like protein, gamma-8 and stargazin in the plasma membrane of hippocampal and cortical neurons. Neurosci. Res., 55, 45-53.

Kitayama, K., Abe, M., Kakizaki, T., Honma, D., Natsume, R., Fukaya, M., Watanabe, M., Miyazaki, J., Mishina, M. \& Sakimura, K. (2001) Purkinje cell-specific and inducible gene recombination system generated from C57BL/6 mouse ES cells. Biochem. Biophys. Res. Commun., 281, 1134-40.

Malinow, R. \& Malenka, R.C. (2002) AMPA receptor trafficking and synaptic plasticity. Annu. Rev. Neurosci., 25, 103-126.

Miyazaki, T., Fukaya, M., Shimizu, H. \& Watanabe, M. (2003) Subtype $\quad$ switching of vesicular glutamate transporters at parallel fibre-Purkinje cell synapses in developing mouse cerebellum. Eur. J. Neurosci., 17, 2563-2572

Mosbacher, J., Schoepfer, R., Monyer, H., Burnashev, N., Sheeburg, P.H., Ruppersberg \& J.P. (1994) A molecular determinant for submillsecond 
desensitization in glutamate receptors. Science, 266, 1059-1062.

Nakamura, K., Manabe, T., Watanabe, M., Mamiya, T., Ichikawa, R., Kiyama, Y., Sanbo, M., Yagi, T., Inoue, Y., Nabeshima, T., Mori, H. \& Mishina, M. (2001) Enhancement of hippocampal LTP, reference memory and sensorimotor gating in mutant mice lacking a telencephalon-specific cell adhesion molecule. Eur. J. Neurosci., 13, 179-189.

Nusser, Z., Lujan, R., Laube, G., Roberts, J.D., Molnar, E. \& Somogyi, P. (1998a) Cell type and pathway dependence of synaptic AMPA receptor number and variability in the hippocampus. Neuron, 21, 545-559.

Nusser, Z., Sieghart, W. \& Somogyi, P. (1998b) Segregation of different GABAA receptors to synaptic and extrasynaptic membranes of cerebellar granule cells. J. Neurosci., 18, 1693-1703.

Ottersen, O.P. \& Landsend, A.S. (1997) Organization of glutamate receptors at the synapse. Eur. J. Neurosci., 9, 2219-2224.

Passafaro, M., Piech, V. \& Sheng, M. (2001) Subunit-specific temporal and spatial patterns of AMPA receptor exocytosis in hippocampal neurons. Nat. Neurosci., $\mathbf{4}$, 917-926.

Rouach, N., Byrd, K., 
Petralia, R.S., Elias, G.M., Adesnik, H., Tomita, S., Karimzadegan, S., Kealey, C., Bredt , D.S. \& Nicoll, R.A. (2005) TARP $\gamma$-8 controls hippocampal AMPA receptor number, distribution and synaptic plasticity. Nat. Neurosci., 8, 1525-1533.

Schnell, E., Sizemore, M., Karimzadegan, S., Chen, L., Bredt, D.S. \& Nicoll, R.A. (2002) Direct interactions between PSD-95 and stargazin control synaptic AMPA receptor number. Proc. Natl. Acad. Sci. USA, 99, 13902-13907.

Sem'yanov, A.V. (2005) Diffusional extrasynaptic neurotransmission via glutamate and GABA. Neurosci. Behav. Physiol., 35, 253-266.

Sharp, A.H., Black, J.L. 3rd, Dubel, S.J., Sundarraj, S., Shen, J.P., Yunker, A.M., Copeland, T.D. \& McEnery, M.W. (2001) Biochemical and anatomical evidence for specialized voltage-dependent calcium channel gamma isoform expression in the epileptic and ataxic mouse, stargazer. Neuroscience, 105, 599-617.

Sheng, M. \& Lee, S.H. (2001) AMPA receptor trafficking and the control of synaptic transmission. Cell, 105, 825-828.

Shibata, T., Yamada, K., Watanabe, M., Ikenaka, K., Wada, K., Tanaka, K. \& Inoue, Y. (1997) Glutamate transporter GLAST is expressed in the radial glia-astrocyte lineage of developing mouse spinal cord. J. Neurosci., 17, 9212-9219.

Shimuta, M., Yoshikawa, M., Fukaya, M., Watanabe, M., Takeshima, H. \& Manabe, T. 
(2001) Postsynaptic modulation of AMPA receptor-mediated synaptic responses and LTP by the type 3 ryanodine receptor. Mol. Cell Neurosci., 17, 921-930.

Song, I. \& Huganir, R.L. (2002) Regulation of AMPA receptors during synaptic plasticity. Trends Neurosci., 25, 578-88.

Takeuchi, T., Nomura, T., Tsujita, M., Suzuki, M., Fuse, T., Mori, H. \& Mishina, M. (2002) Flp recombinase transgenic mice of C57BL/6 strain for conditional gene targeting. Biochem. Biophys. Res. Commun., 293, 953-957.

Tomita, S., Chen, L., Kawasaki, Y., Petralia, R.S., Wenthold, R.J., Nicoll, R.A. \& Bredt, D.S. (2003) Functional studies and distribution define a family of transmembrane AMPA receptor regulatory proteins. J. Cell Biol., 161, 805-816.

Tomita, S., Fukata, M., Nicoll, R.A. \& Bredt, D.S. (2004) Dynamic interaction of stargazing-like TARPs with cycling AMPA receptors at synapses. Science, 303, $1508-1511$.

Tomita S, Stein V, Stocker TJ, Nicoll RA, Bredt DS (2005a) Bidirectional synaptic plasticity regulated by phosphorylation of stargazin-like TARPs. Neuron $45: 269-277$.

Tomita, S., Adesnik, H., Sekiguchi, M., Zhang, W., Wada, K., Howe, J.R., Nicoll, R.A. 
\& Bredt, D.S. (2005b) Stargazin modulates AMPA receptor gating and trafficking by distinct domains. Nature, 435, 1052-1058.

Vandenberghe, W., Nicoll, R.A. \& Bredt, D.S. (2005) Interaction with the unfolded protein response reveals a role for stargazin in biosynthetic AMPA receptor transport. J. Neurosci., 25, 1095-1102

Verdoorn, T.A., Burnashev, N., Monyer, H., Seeburg, P.H. \& Sakmann, B. (1991) Structural determinations of ion flow through recombinant glutamate receptor channels. Science, 252,1715-1718.

Watanabe, M., Fukaya, M., Sakimura, K., Manabe, T., Mishina, M. \& Inoue, Y. (1998) Selective scarcity of NMDA receptor channel subunits in the stratum lucidum (mossy fibre -recipient layer) of the mouse hippocampal CA3 subfield. Eur. J. Neurosci., 10, 478-487.

Yamada, K., Fukaya, M., Shimizu, H., Sakimura, K. \& Watanabe, M. (2001)

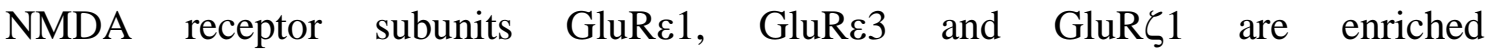
at the mossy fibre-granule cell synapse in the adult mouse cerebellum. Eur. J. Neurosci., 13, 2025-2036.

Yamazaki, M., Ohno-Shosaku, T., Fukaya, M., Kano, M., Watanabe, M. \& Sakimura, K. (2004) A novel action of stargazin as an enhancer of AMPA receptor activity. Neurosci. Res., 50, 369-374. 


\section{Figure Legends}

Fig. 1. Biochemical distribution and protein solubility of TARP $\gamma-8$ in the adult mouse brain. $(A, B)$ Immunoblot showing the highest concentration of $\gamma-8$ and AMPA receptors in the hippocampus (Hi). In each lane, 10 $\mu \mathrm{g}$ of proteins was loaded. Values on individual columns represent percent values relative to the levels in hippocampal homogenate. Acti $\mathrm{n}$ is shown to the bottom. $(C, \quad D)$ Different solubility among $\gamma-8, \quad$ AMPA receptors, GluRe2, and PSD-95. The synaptosomal fraction of the hippocampus was solubilized with increasing concentrations of Triton X-100 (TX). In each lane, 3 $\mu \mathrm{g}$ of proteins was loaded. Values on individual columns represent the percentage values relative to the levels in the synaptosomal fracti on (i.e., 0\% Triton X-100). Each column represents the mean value from three to four experiments. Bars on columns represent s.e.m. Cb, cerebellum; CP, caudate-putamen; Cx, cortex; Md/Di, midbrain/diencephalon; MO/Pn, medulla oblongata/pons; OB, olfactory bulb.

Fig. 2. Confocal laser scanning microscopy showing cellular and subcellular distribution of $\gamma-8$ in hippocampal microslicer sections. $(A, B)$ Specificity and overall distribution of $\gamma$-8 immunofluorescence. Note characteristic labeling in the wild-type mouse brain $(A)$, but not in the $\gamma$-8-KO mouse brain $(B)$. $(C, D)$ Intense immunolabeling for $\gamma$-8 in the hippocampus. (E-G) Double immunofluorescence with glutamatergic terminal marker VGluT1 in the CA1 $(E)$ and CA3 $(F)$ regions and with glial marker GLAST in the CA3 region $(G)$. $(H-K)$ Double immunofluorescence for $\gamma-8$ 
and AMPA receptors using pan-AMPA receptor antibody. Prior to immunohistochemical incubation, microslicer sections were pretreated with 1 $\mathrm{mg} / \mathrm{ml}$ of pepsin at $37^{\circ} \mathrm{C}$ for $0 \mathrm{~min}(H), 1 \mathrm{~min}(I)$, and $3 \mathrm{~min}(J, K)$. The gain level of confocal microscope was the same for images in $H$-J. Large and small arrows in $(K)$ indicate surface labeling on dendritic shafts of putative pyramidal cells and interneurons, respectively. CA1, 3, CA1 and CA3 regions; Cb, cerebellum; CP, caudate-putamen; $\quad \mathrm{Cx}, \quad$ cortex; $\quad$ DG, dentate gyrus; $\mathrm{Gr}$, granular layer; Hip, hippocampus; Ht, hypothalamus; IC, inferior colliculus; LM, stratum lacunosum-moleculare; Lu, stratum lucidum; MB, midbrain; MO, medulla oblongata; Mo, molecular layer; OB, olfactory bulb; Or, stratum oriens; PM, polymorphic layer; Po, pons; Py, pyramidal cell layer; Ra, stratum radiatum; SN, substantia nigra; Th, thalamus; I VI, laminae I VI; Scale bars, $A, B, 1 \mathrm{~mm} ; C, H-J, 0.1$ $\mathrm{mm} ; D-G, K, 10 \mu \mathrm{m}$.

Fig. 3. Immunogold electron microscopy showing the subcellular localization of $\gamma-8$ in the hippocampus of C57BL/6 wild-type mice. $(A-C)$ Preembedding silver-enhanced immunogold in the pyramidal cell layer $(\mathrm{Py}, A)$ and stratum radiatum $(\mathrm{Ra}, B, C)$ of the CA1. Arrowheads indicate silver particles on the plasma membrane of pyramidal cell somata $(A)$ and dendrite $(B, \quad P D n)$. $(D-H)$ Postembedding immunogold in the stratum radiatum of control CA1 $(D, F)$ and $\gamma$-8-KO CA1 (E), and in the stratum radiatum $(G)$ and stratum lucidum $(\mathrm{Lu}) \quad(H)$ of wild-type CA3. Arrows in $D$ and $G$ indicate gold particles on the extrasynaptic membrane. (I-L) Quantitative analyses for subcellular localization of $\gamma-8$ with post(I-K) and preembedding (L) immunogold methods. (I) The percentage of 
gold particles for plasma membrane-associated labeling and intracellular labeling in spines of the CA1 stratum radiatum. $n=168$ for total particles analyzed. ( $J$ The mean number of metal particles per $1 \mu \mathrm{m}$ of the synaptic (Syn) and extrasynaptic (Extra) membranes in spines of the CA1 stratum radiatum. The total length measured is $13.1 \mu \mathrm{m}$ for postsynaptic membrane and 12.2 $\mu \mathrm{m}$ for extrasynaptic membrane. $(K)$ The mean number of gold particles per synaptic profile of asymmetrical (As) and symmetrical (Sy) synapses. The numbers of asymmetrical synapses analyzed are 58 and 19 for axo-spinous (Sp-As) or axo-dendritic (Dn-As) synapses in the CA1 stratum radiatum, respectively, and 60 and 48 for axo-spinous synapses (Sp-As) in the CA3 stratum radiatum and stratum lucidum (i.e., mossy fiber-CA3 synapses), respectively. The number of symmetrical synapses analyzed (Dn-Sy) is 11 in the CA1 stratum radiatum. Error bars indicate s.e.m. $(L)$ The mean number of silver particles per $1 \mu \mathrm{m}$ of postsynaptic membrane (Synapse; measured membrane length, $25 \mu \mathrm{m}$ ), extrasynaptic membranes (Extrasynapse) on spines $(141 \mu \mathrm{m})$, dendritic shafts $(110 \mu \mathrm{m})$, cell body (33 $\mu \mathrm{m})$, and presynaptic terminal membrane (terminal; $58 \mu \mathrm{m}$ ) in the CA1 stratum radiatum. ER, endoplasmic reticulum or spine apparatus; IDn, interneuron dendrite; MF, mossy fiber terminal; NT, nerve terminal; PN, pyramidal cell nucleus; Sp, spine. Scale bars, $500 \mathrm{~nm}$ in $A$ and $B ; 100 \mathrm{~nm}$ in $C-H$.

Fig. 4. Production of $\gamma-8-\mathrm{KO}$ mice by Cre/loxP recombination system. (A) Schematic representation of $\gamma-8$ cDNA, $\gamma-8^{+}$allele $\left(\gamma-8^{+}\right)$, targeting vector (Vector), targeted $\gamma-8^{\text {flox-neo }}$ allele $\left(\gamma-8^{\text {flox }}\right)$, and knockout $\gamma-8^{-}$allele $\left(\gamma-8^{-}\right)$ after Cre-mediated recombination. Gray boxes represent the transmembrane segments $\mathrm{T}$ 
M1 to TM4, while open boxes represent exon sequences, pgk-promoter-neo-pA (neo) cassette and diphtheria toxin (DT) cassette. LoxP and frt sites are indicated by black triangles and open circles, respectively. Black bars indicate probe regions (5', neo, and 3') used for Southern blot analysis. B, Bgl II; S, SpeI; K, Kpn I. (B) Southern blot analysis for genomic DNAs from $\gamma-8^{+/+}(+/+), \gamma-8^{+/ \text {flox-neo }}(+/$ flox $)$ ES cells. Left, Bgl II-digested DNA hybridized with 5' probe; $\begin{array}{llll}\text { middle, } & \text { Bgl } & \text { II-digested } & \text { DNA }\end{array}$ with neo probe; right, Kpn I-digested DNA hybridized with 3' probe. Positions of DNA size markers (kbp) are indicated to the left. (C) Southern blot analysis for genomic DNAs from $\gamma-8^{+/+}(\mathrm{WT}), \quad \gamma-8^{+/-}$(Hetero) and $\gamma-8^{-/-}$(KO) mice. SpeI-digested DNA hybridized with 5'in probe. Positions of DNA size markers $(\mathrm{kbp})$ are indicated to the left. $(D, E)$ Immunoblot analysis for $\gamma-8$, AMPA receptors, GluRe2, and PSD-95 in the S1, P2, P3 and PSD fractions prepared from WT and $\gamma-8-\mathrm{KO}$ mice. Proteins loaded in each lane are 10 $\mu \mathrm{g}$ for the S1, P2, P3 fractions and $3 \mu \mathrm{g}$ for the PSD fraction. Values on columns in $E$ show the mean percentage relative to corresponding fractions prepared from control mice. Bars on individual columns represent s.e.m. $\mathrm{n}=3$ experiments. $(F-H)$ Normal histology of the brain and hippocampus between WT and $\gamma-8-\mathrm{KO}$ mice. See abbreviations for Fig. 2. Scale bars, F, 1mm; G, H, $0.1 \mathrm{~mm}$.

Fig. 5. Immunofluorescence for AMPA receptors and immunoperoxidase for GluR $\zeta 1$ and VGluT1 in the hippocampi of control and $\gamma-8-\mathrm{KO}$ mice. $(A, B)$ Marked decrease of AMPA receptor immunofluorescence in $\gamma-8-\mathrm{KO}$ hippocampus. Microslicer 
sections were pretreated with pepsin digestion for $3 \mathrm{~min}$. Arrows indicate the pyramidal cell layer. (C-F) Normal immunoperoxidase distribution for NMDA receptor GluR $\zeta 1$ $(C, D)$ and VGluT1 $(E, F)$ in the hippocampus. Paraffin sections were pretreated with pepsin digestion for 10 min. $(G-L)$ AMPA receptor immunofluorescence in the CA1 $(G, J)$, CA3 $(H, K)$ and dentate gyrus $(I, L)$ of control $(G-I)$ and $\gamma-8-\mathrm{KO}(J-L)$ mice. Microslicer sections were digested with pepsin for 3 min. See abbreviations for Fig. 2. Scale bars, $A-F, 0.1 \mathrm{~mm}$; $G-L, 10 \mu \mathrm{m}$.

Fig. 6. Quantitative assessment of changes in synaptic AMPA receptors by postembedding immunogold using pan-AMPA antibody. $(A-F)$ Electron micrographs from wild-type $(A, C, E)$ and $\gamma-8-K O(B, D, F)$ mice for pan-AMPA $(A, B, E, F)$ and $\operatorname{GluR} \zeta 1(C, D)$ in the CA1 stratum radiatum (Ra) $(A-D)$ and the CA3 stratum lucidum $(\mathrm{Lu})(E, F)$. $(G-J)$ The mean number of immunogold particles for pan-AMPA $(G, I, J)$ and GluR $\zeta 1(H)$ per synaptic profiles of asymmetrical axo-spinous synapse in the CA1 stratum radiatum $(G, H)$, CA3 stratum radiatum (I), and CA3 stratum lucidum $(J)$. Light and dark gray columns represent scores for control and $\gamma-8-\mathrm{KO}$ mice, respectively. Error bars indicate s.e.m. Asterisks indicate statistical significance $(p<0.05, t$ test). MF, mossy fiber terminal; NT, nerve terminal; Sp, spine. Scale bars, $100 \mathrm{~nm}$.

Fig. 7. Quantitative assessment of changes in extrasynaptic and intracellular AMPA receptors by preembedding silver-enhanced immunogold method using GluR $\alpha 1$ antibody. $(A, B)$ Light microscopic GluR $\alpha 1$ labeling in control $(A)$ and $\gamma$-8-KO (B) mice. Note marked reduction in dendritic layers of the CA1 region. 
$(C-H)$ Electron microscopic GluR $\alpha 1$ labeling in the CA1 region of control $(C-E)$ and $\gamma$-8-KO $(F-H)$ mice. (I) Mean number of silver particles per spine in the CA1 stratum radiatum. Note a marked reduction of plasma membrane-associated labeling. $(J)$ Mean number of silver particles per $1 \mu \mathrm{m}$ of the synaptic (synapse) and extrasynaptic (extrasynapse) membranes in the spine, dendrite, and cell body, and of nerve terminal membrane in the CA1 stratum radiatum. The total measured length in the control and $\gamma$-8-KO mice is 37.7 and $33.7 \mu \mathrm{m}$ for postsynaptic membrane, 189 and $202 \mu \mathrm{m}$ for extrasynaptic spine membrane, 148 and $118 \mu \mathrm{m}$ for extrasynaptic dendritic membrane, 27 and $26 \mu \mathrm{m}$ for extrasynaptic somatic membrane, and 132.5 and 119.7 $\mu \mathrm{m}$ for presynaptic terminal membrane, respectively. Error bars indicate s.e.m. Asterisks represent statistical significance ( $p<0.01, t$ test). LM, stratum lacunosum-moleculare; NT, nerve terminal; Or, stratum oriens; Py, pyramidal cell layer; Ra, stratum radiatum; Sp, spine. Scale bars, $A, B, 100 \mu \mathrm{m} ; C-H, 100 \mathrm{~nm}$. 


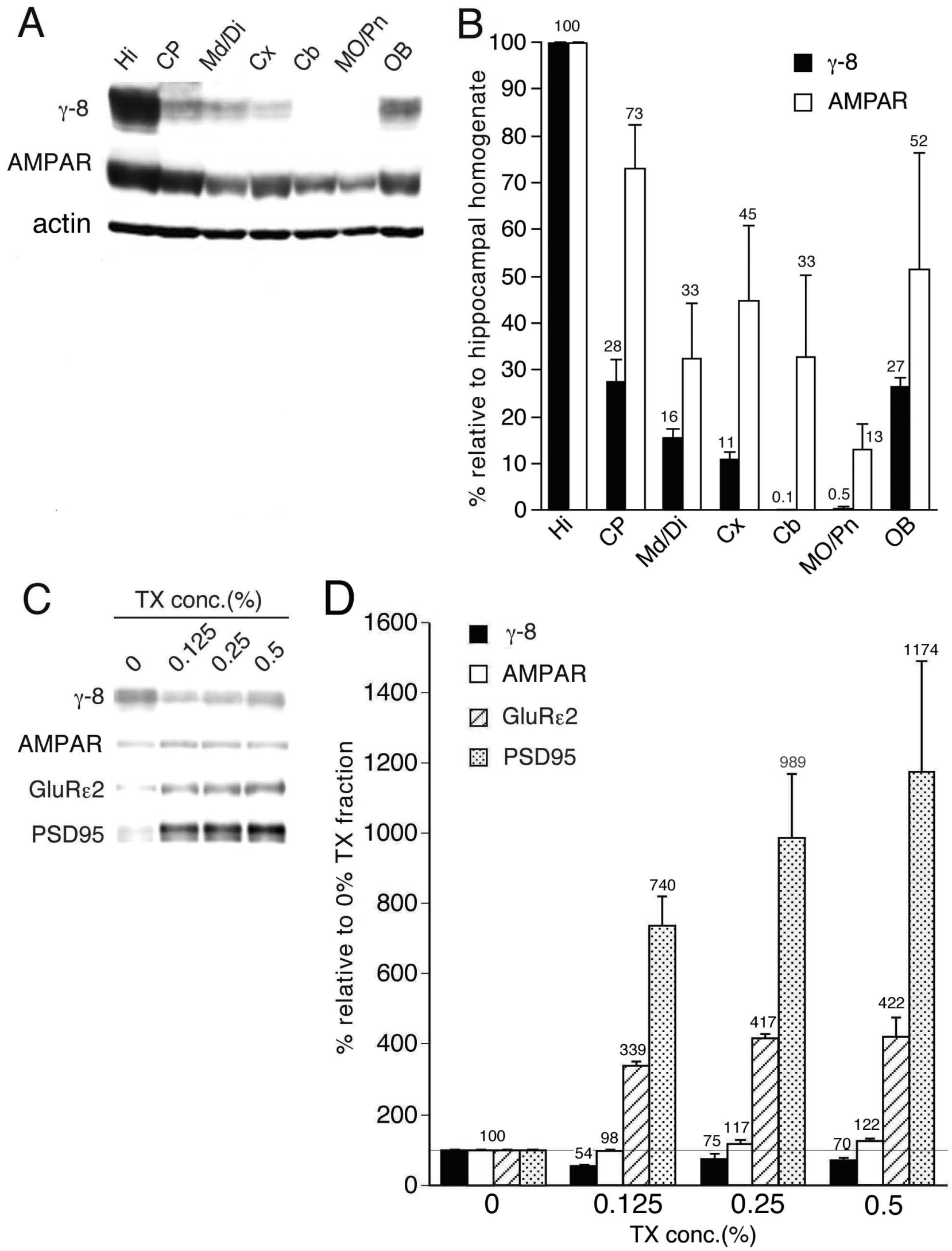

Figure 1 

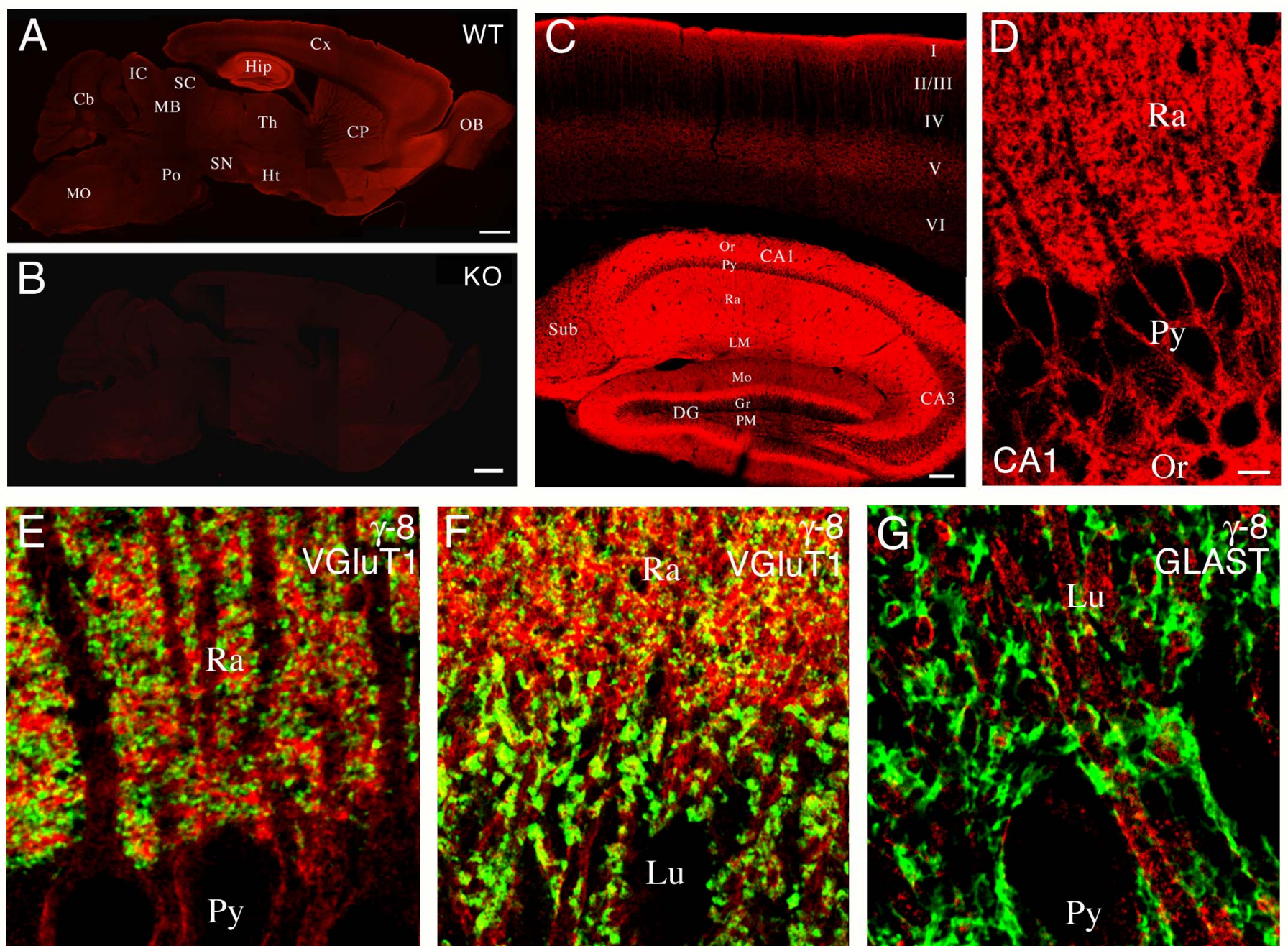

CA1
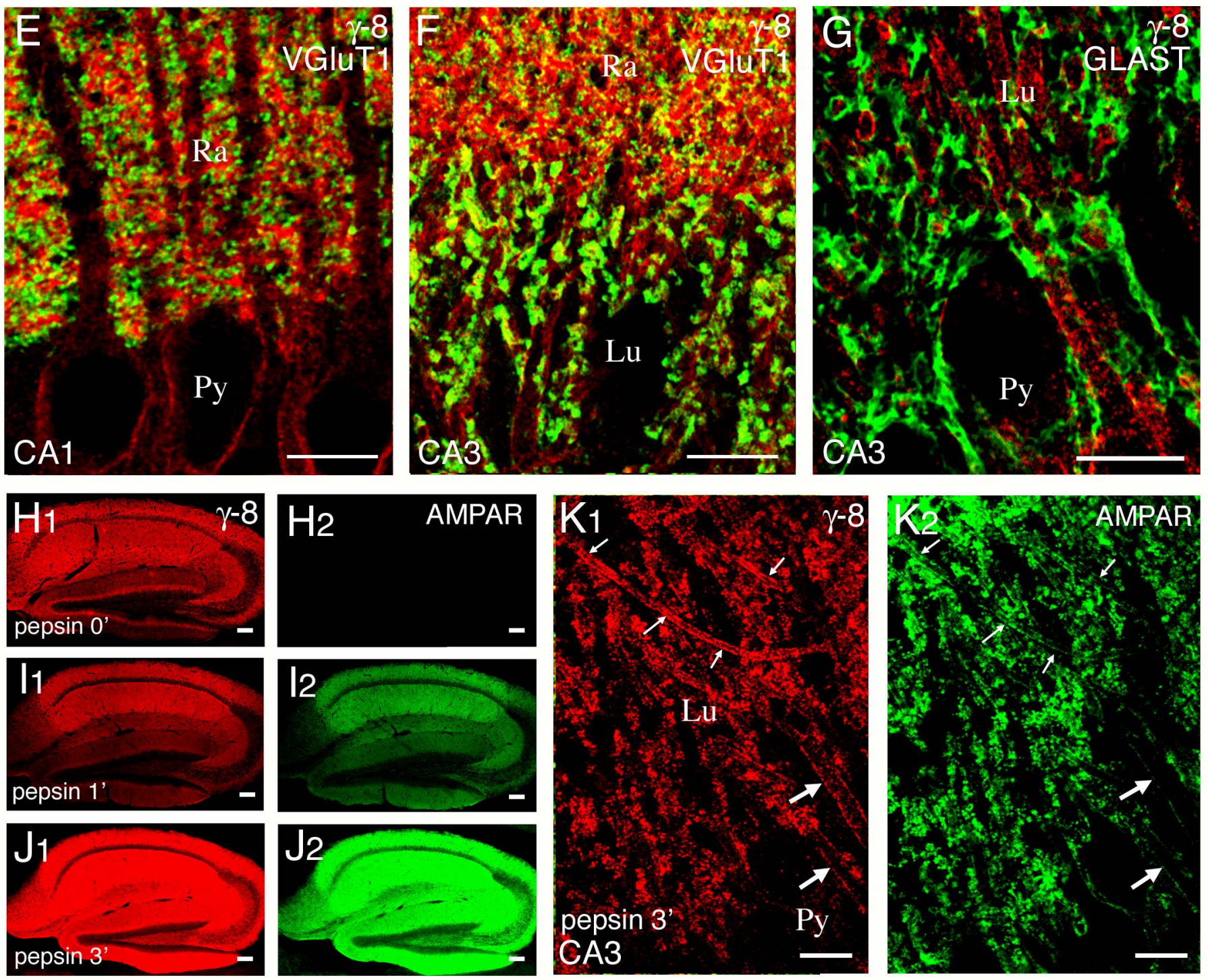

Figure 2 

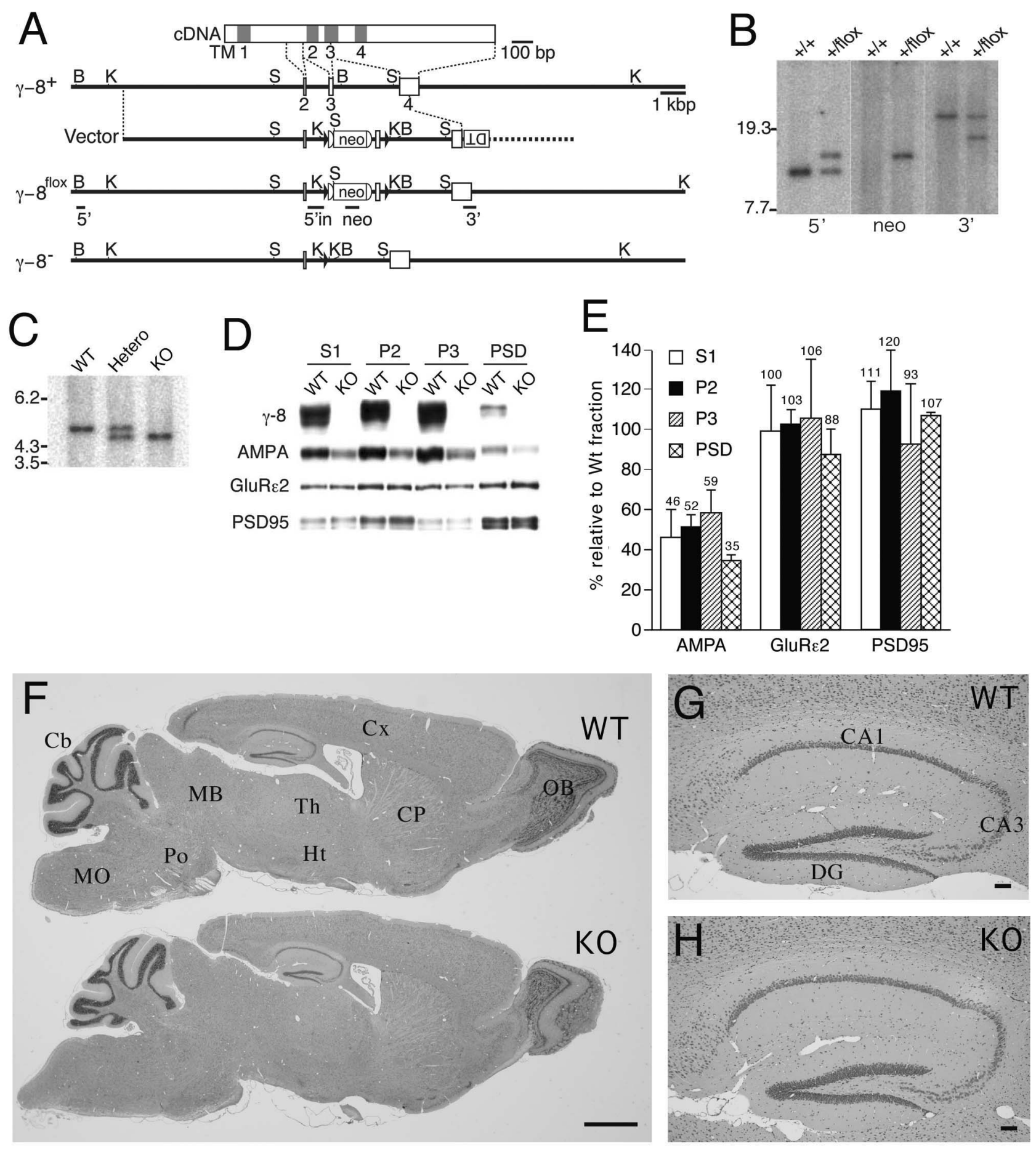

Figure 4 

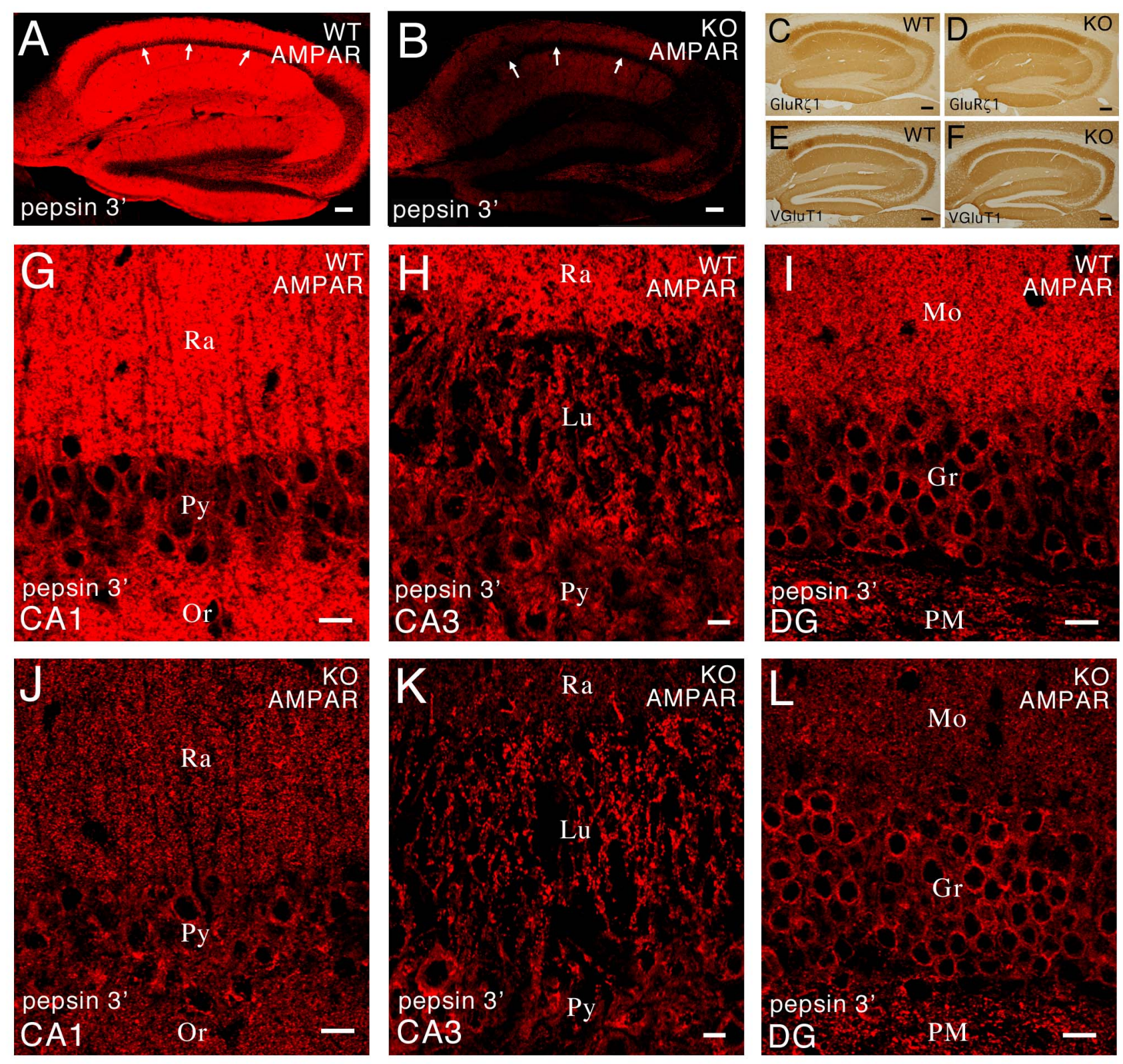

Figure 5 


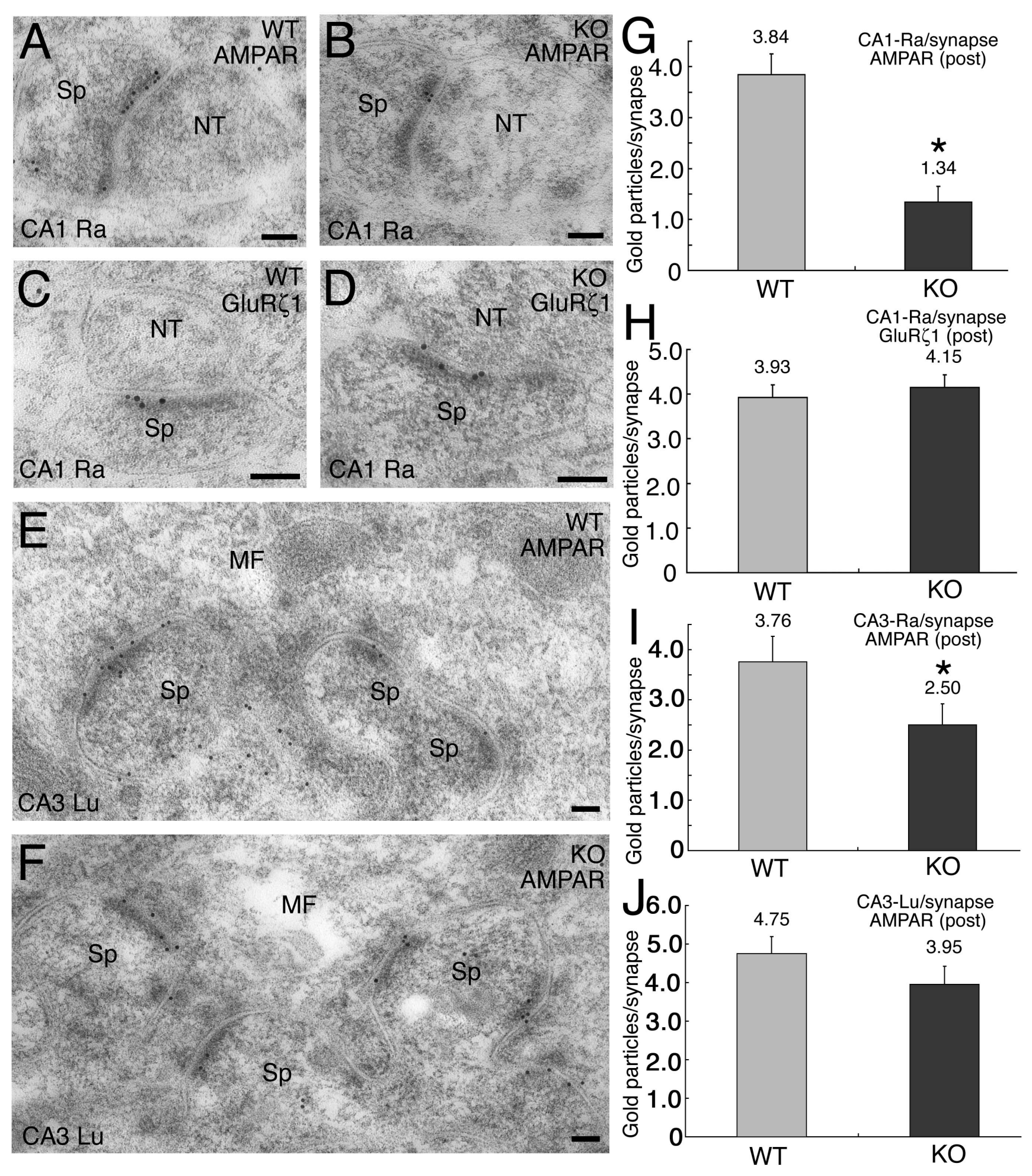

Fukaya et al. Figure 6 


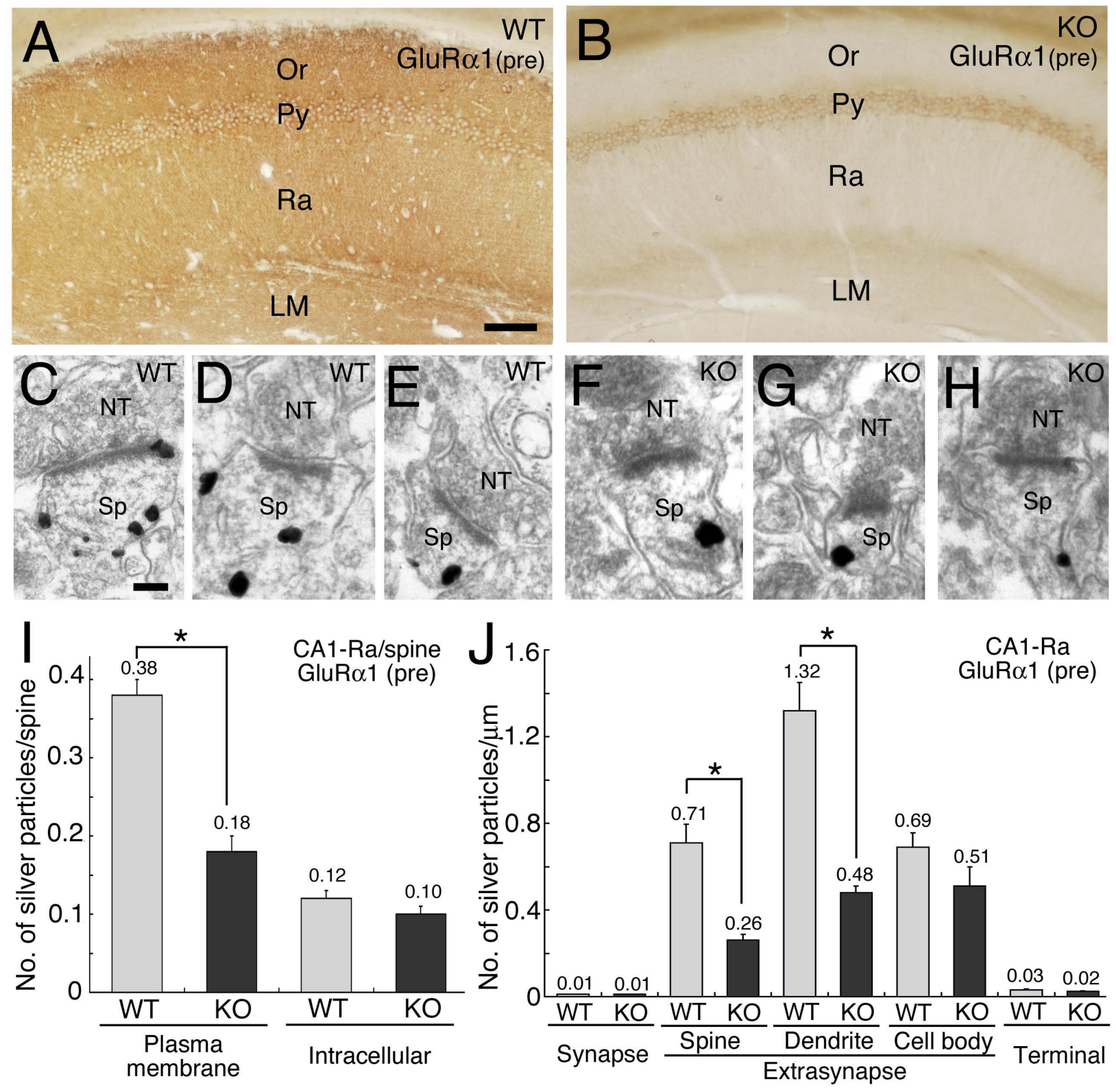

Fukaya et al.

Figure 7 
Supplemental Materials

Supplemental Fig. S1. Production and specificity of pan-AMPA receptor antibody. $(A)$ Amino acid sequences used for antigen (Ag, 717-754 amino acid residues of GluRa1) and affinity purification (Af, 727-745). Corresponding regions of other GluR subunits are aligned. Red and blue residues show identical amino acids to all these subunits or to AMPA receptor subunits, respectively. $(B, C)$ Immunoperoxidase with guinea pig pan-AMPA receptor antibody on parasagittal paraffin sections. Absorption of antibody with antigen abolishes immunostaining $(C)$. $(D)$ Immunoblot with pan-AMPA receptor antibody for cerebral (cerebrum) and cerebellar (cerebellum) homogenates, COS7 cell lysates transfected with AMPA receptor subunits (GluR $\alpha 1-\alpha 4)$ and kainate receptor subunit (GluRß2 or GluR6), and untransfected lysates (COS7).

Supplemental Fig. S2. Immunoperoxidase using antibodies to pan-AMPA receptors $(A-J)$, GluR $\alpha 1$ subunit $(K-P)$, and GluR $\alpha 2$ subunit $(Q-V)$ in the hippocampus of control and $\gamma-8-\mathrm{KO}$ mice. $G-J$ are enlarged views from the CA1 $(G, I)$ and CA3 $(H, J)$ regions. Note reduced immunoperoxidase staining in dendritic layers of $\gamma-8-\mathrm{KO}$ hippocampus, which is consistent with immunofluorescence staining (Fig. 5). Also note stronger perikaryal staining in $\gamma$-8-KO hippocampus for AMPA receptors, GluR $\alpha 1$ subunit, and GluRa2 subunit in CA1 and CA3 pyramidal cells, which is not appreciated from immunofluorescence staining (Fig. 5). See abbreviations for Fig. 2. Scale bars, $A-F, K-V$, $0.1 \mathrm{~mm} ; \mathrm{G}-J, 10 \mu \mathrm{m}$. 
Af

GluR $\alpha$ (717-754) LLESTMNEYIEQRKPCDTMKVGGNLDSKGYGIATPKGS GluR $\alpha 2$ (724-761) LLESTMNEYIEQRKPCDTMKVGGNLDSKGYGIATPKGS GluR $\alpha 3$ (729-766) LLESTMNEYIEQRKPCDTMKVGGNLDSKGYGVATPKGS GluR $\alpha 4$ (725-762) LLESTMNEYTEQRKPCDTMKVGGNLDSKGYGVATPKGS GluR5 (750-787) LLMESTSIEYVTQRNCNLTQIGGLIDSKGYGVGTPIGS GluR6 (735-772) FLMESTTIEFVTQRNCNLTQIGGLIDSKGYGVGTPMGS GluR7 (705-742) LLMESTTIEYITQRNCNLTQIGGLIDSKGYGIGTPMGS KA1 (720-757) FLLESTMNEYYRQRNCNLTQIGGLLDTKGYGIGMPVGS KA2 (719-756) FLLESTMNEYHRRLNCNLTQIGGLLDTKGYGIGMPLGS GluR82 (741-778) WDAAVLEYVAINDPDCSFYTVGNTVADRGYGIALQHGS GluR'1 (731-776) WDSAVLEFEAS-QK-CDLVTTGELFFRSGFGIGMRKDS GluRe1 (732-769) AAVLNYKAGRDEGCKLVTIGSGYIFATTGYGIALQKGS
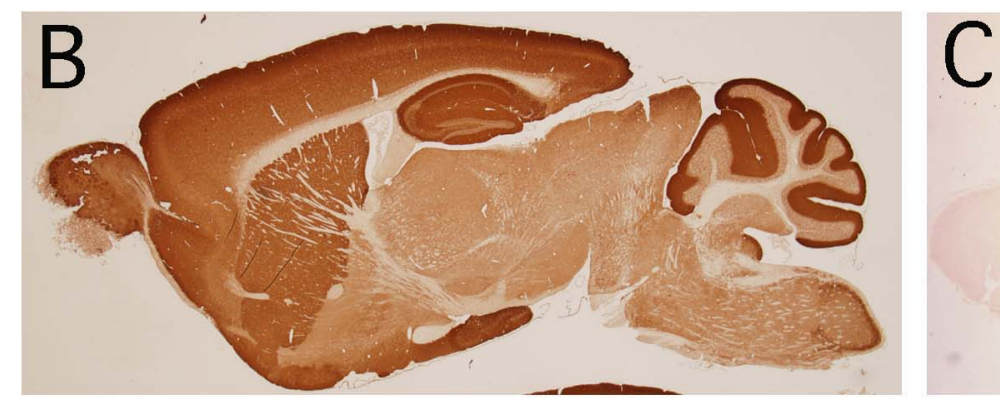

D

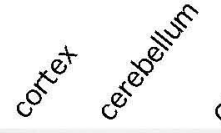

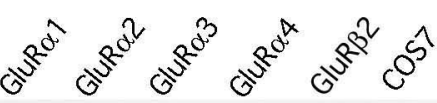

201-

$118-$

$83-$

48-

\section{Supplemental Fig. 1}




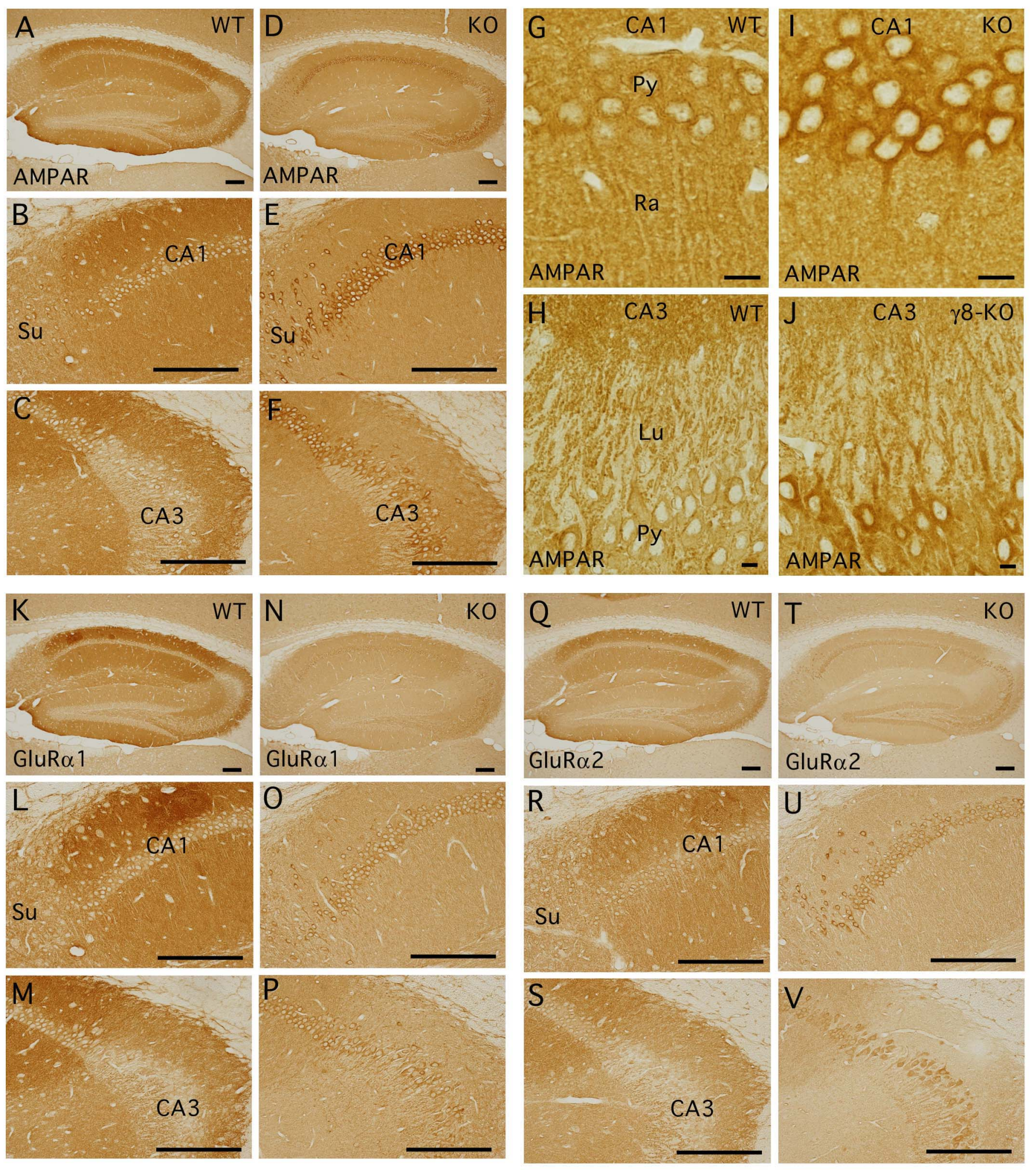

Supplemental Fig. 2 